University of Zurich

Department of Economics

Working Paper Series

ISSN 1664-7041 (print)

ISSN 1664-705X (online)

Working Paper No. 289

\title{
Eu transfers and euroscepticism: can't buy me love?
}

Alessandro Borin, Elisa Macchi and Michele Mancini

June 2018 


\title{
EU TRANSFERS AND EUROSCEPTICISM: CAN'T BUY ME LOVE?
}

\author{
by Alessandro Borin*, Elisa Macchi ${ }^{\S}$ and Michele Mancini*
}

June 2018

\begin{abstract}
$^{1}$
This paper investigates whether EU redistributive policies improved the public attitude toward European integration, both in terms of public opinion and in terms of political preferences. We build a new dataset combining data from the European Social Survey, different data sources for political parties' stances and transfer records from EU institutions. We focus on the regional Cohesion Policy, within which the Convergence Objective program offers a quasi-experimental framework that allows us to single out these effects by means of a regression discontinuity approach. Results show that EU transfers have mitigated the rise of Eurosceptic attitudes and reduced the political consensus for antiEU parties in long-time recipient regions. We estimate that increasing the regional per capita EU transfers by $1000 €$ over the 2000-2014 period reduces the share of Eurosceptic individuals by about 8 percentage points and voters' support for anti-EU parties by 10 percentage points. The effects are homogeneous across different socio-economic groups, including the most disadvantaged ones. Other attitudes that are often associated with Euroscepticism (i.e. anti-trade and anti-immigration stances) are not substantially affected by EU regional transfers.
\end{abstract}

JEL Classification: D72, F14, H11, I38

Keywords: Euroscepticism; EU transfers; EU crisis; Cohesion Policy; voting; regression discontinuity, redistributive politics.

\footnotetext{
* Bank of Italy, Economics and Statistics Department $\S$ University of Zurich

${ }^{1}$ We would like to thank Sara Bagagli, Pietro Catte, Giuseppe Sorrenti, Giovanni Veronese and David YanagizawaDrott for their comments. The views here expressed are those of the authors and should not be attributed to the Bank of Italy.
} 


\section{Introduction}

Over the past few years, resentment toward the European Union has been spreading throughout Europe. So far, the victory of the "Leave" campaign in the 2016 Brexit referendum was probably the most noticeable and politically relevant outcome of this trend. However, different sources show that disaffection with the European Union is not - or no longer - a distinctive feature of the Britons, but has been on the rise in almost all the EU member states, ${ }^{2}$ a trend that has exacerbated after the financial crisis. ${ }^{3}$

Discussing possible reactions to these trends, several commenters have recommended a more active role for EU policies, ${ }^{4}$ both by supporting the recovery in countries most seriously hit by the crisis and by contributing to reduce job displacement and other negative consequences of globalization and technological change. According to their advocates, stronger redistributive policies could improve the citizens' attitude toward the EU both directly, by making the benefits from the EU membership more tangible, and indirectly, by alleviating the economic distress which fuels social discontent.

In this paper we investigate how EU transfers influence citizens' attitudes toward European integration, and how this is reflected in electoral support for pro-EU parties. Our work represents the first attempt to on one hand, rigorously investigate the causal effect of EU transfers on mitigating Euroscepticism and on the other hand, to and to shed light on whether enhancing fiscal solidarity among member states could "buy" political support to the EU. By looking at indirect transfers (i.e. not directly assigned to citizens), for the first time we show that the vote buying effect of redistribution holds true also for this transfers' category.

We focus on the effect of European regional Cohesion Policy on public support for European integration in the EU-15 (i.e. the Union member states before the 2004 enlargement) and we exploit information from the European Social Survey (ESS) about European citizens' attitudes and pro-/anti-EU political preferences. The European Cohesion Policy funding represents the core EU policy aiming at reducing regional disparities (Bachtler et al., 2013). ${ }^{5}$ Moreover, despite being

\footnotetext{
${ }^{2}$ See, among others, van Erkel and van der Meer (2016) and Biancotti et al. (2017).

${ }^{3}$ Colantone and Stanig (2018) reveal that nationalistic parties - which usually express unfavourable stances on the EU - tend to be more popular in those European regions that suffered the harshest competition from developing countries; van Erkel et al. (2016), Hobolt and de Vries (2016), Foster and Frieden (2017) show that this trend has been exacerbated by the deterioration of economic conditions determined by the financial crises; Guiso et al. (2018) find that after the crisis confidence in European institutions has dropped much more markedly in the euro area countries as compared to non-euro area EU ones; and, among the former countries, trust in the EU deteriorated in particular where macroeconomic worsened the most.

${ }^{4}$ See, among others, Dustmann et al. (2017), Algan et al. (2017), Gamble, (2017), Boeri and Jimeno (2016).

${ }^{5}$ EU Cohesion Policy was first established in 1986 with the Objective of tackling economic and social disparities between the levels of development in different EU regions. The funding is based on three main instruments (i.e. three of the five Structural and Investment funds): the European Regional Development Fund (ERDF), the European Social Fund (ESF) and the Cohesion Fund (CF). Its implementation involves the regions and the member states to a significant degree: first, the EU Commission negotiates and approves the priorities proposed by member states (National Strategic Reference Framework, NSRF) and regions (Operational Programmes, OPs) and, basing on these, allocates resources; then member states and regions are in charge of managing the programs (i.e. selecting
} 
mainly destined to structural investment, they are large enough to be appreciated by the population (see Fig. 1).

The main challenge we face in our investigation is that EU Cohesion Policy transfers are not randomly allocated. By definition, EU Cohesion Policy are mostly targeted to less developed regions, that should benefit from proportionally higher transfers. However, the final amount received by each region is determined by the number and the worth of the projects approved, which in turn depends on a series of institutional, political and socio-economic factors; this might disadvantage the poorest regions. As factors correlated with the regional development level are also likely to be correlated with the attitude toward the EU, an exogenous variation in transfers is required to be able to estimate the causal effect of the transfers on EU perception.

Figure 1

Examples of the contribution of EU Cohesion Policy Funds to public work projects

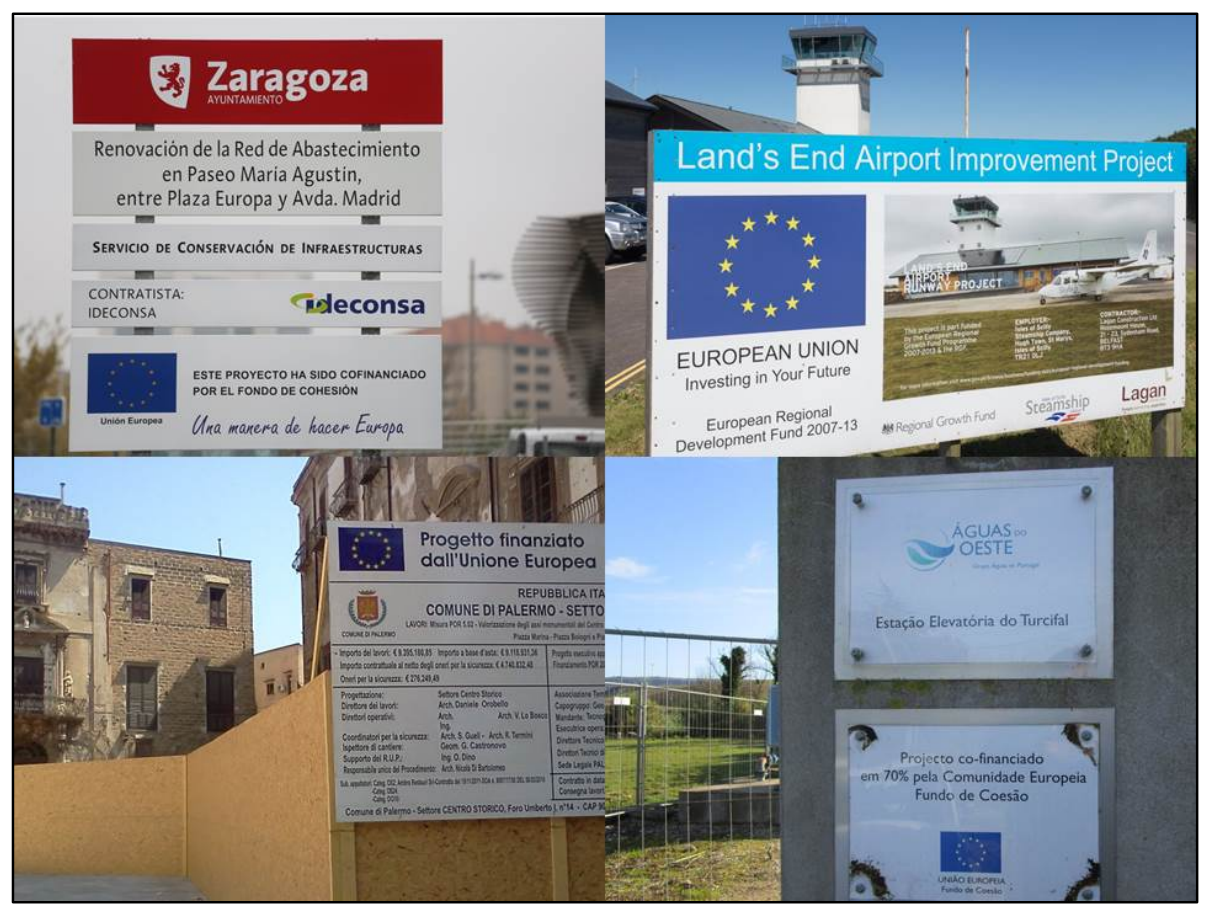

In this analysis, we exploit the exogenous variation generated by the Cohesion Policy assignment rule, which gives rise to a regression discontinuity design (RDD) framework (Becker et al., 2010). In short, the EU Cohesion Policy is articulated in 3 sub-programs (or Objectives); each one is allocated a budget and targets a specific set of regions according to their initial GDP per capita. In particular, regions whose GDP p.c. is just below $75 \%$ of the EU average are targeted by

individual projects, controlling and assessing them); finally, the Commission supervises the program, disburses money for approved expenditure and verifies the national control systems. 
the Convergence Objective and obtain significantly larger funds than those just above the $75 \%$ cutoff. This is the discontinuity our empirical strategy exploits.

The RDD results show that EU transfers have a positive impact on the public support for European integration and reduce the propensity to vote for anti-EU parties. We estimate that a $1000 €$ increase in the per capita funds received over the 2000-2014 period reduces the share of Eurosceptic individuals by about 8 percentage points and voters' support for anti-EU parties by 10 percentage points. The effects are homogeneous across different socio-economic groups, including more vulnerable individuals (i.e. those highly exposed to the backlash of globalization and technological change, who usually are more prone to embrace anti-establishment positions). Our results are robust to different identification strategies, model specifications, changes in reference period and in the set of regions included in the analysis. The effects appear specific to sentiment toward the EU, while other attitudes often associated with Euroscepticism (i.e. anti-trade and antiimmigration) are not substantially affected by the funding. Intuitively, individuals in distressed economic situations tend to be particularly sceptical toward international-integration policies; however, in a context in which the EU provides financial support, the Union is less likely to be picked as the main target of this aversion.

This paper talks to the topical debate about the shape of EU integration. In academic circles, and to some extent also in political fora, the incompleteness of the EU's architecture is regarded as a key driver of the recent economic and political crises. For proponents of this view further integration is considered essential to guarantee the survival of the EU project. ${ }^{6}$ Different views have been put forward regarding the actual degree of integration to be achieved, and on how the process should take place. Nevertheless, most proposals share the idea that fiscal cooperation should be enhanced, especially within the Monetary Union (EMU), and that financial transfers among the members should be increased and made more effective. Deeper integration of budgetary policies and additional EU budgetary capacity are advocated in order both to pursue greater structural convergence across regions, and to enhance countercyclical policies and social security nets. A particular emphasis has been placed on the reform of Cohesion policies and on the strengthening of instruments designed to reduce long-term unemployment, like the European Social Fund and the European Globalization Adjustment Fund (see Bénassy-Quéré, 2017 and Algan et al. 2017). Debating pros and cons of a fiscal union within the EMU, Balassone et al. (2014) posit that "sharing part of their welfare system, European citizens would gradually learn its benefits and the whole process of the European integration would re-gain legitimacy and momentum".

\footnotetext{
${ }^{6}$ See, among others, Juncker et al. (2015), Fisher (2015), Enderlein et al. (2016), Corsetti et al. (2016), Bénassy-Quéré and Giavazzi (2017), De Grawle (2017), Rome Declaration of March 2017, European Commision (2017).
} 
Our analysis contributes to the discussion by addressing a core point: could devoting more EU resources to pro-growth, pro-employment policies and social security programs benefit the EU's image, especially among the most disadvantaged groups?

The answer is not straightforward. First, the literature still debates whether EU transfers have been effective in fostering growth and job creation. ${ }^{7}$ Abstracting from the policy's direct effects, it is not obvious that the public opinion would be aware of the transfers existence. Indeed, national and local administrations usually participate in the implementation of EU funding schemes and they have a clear incentive to overstate their role at the expense of the EU contribution. ${ }^{8}$ Moreover, political propaganda has often shown an unfavourable bias toward the EU, conveniently used as a scapegoat for unpopular policies without the risk of sanctions. ${ }^{9}$ These mechanisms and confounders might offset - or downplay - an otherwise positive effect of European transfers on public attitudes toward EU membership. In this regard, the Brexit referendum offers an interesting example. The win of the Leave campaign in Cornwall, a region that has largely benefitted from EU funding, has been often taken as evidence of the negligible effect of EU transfers on political preferences. ${ }^{10}$ However, the referendum outcome was heavily influenced by the propaganda of the Leave campaign and other idiosyncratic factors. Moreover, notably, EU funds are mainly directed toward most disadvantaged areas, and it is clear that regions like Cornwall differ in may dimensions from, let's say, the cosmopolitan and richer urban area of London; proper terms of comparison are needed. In other words, the question poses challenges from an econometric perspective as funds' allocation is determined by regional economic status, with richer regions receiving less money, and therefore it is far from exogenous. This is precisely what we try to address with our analysis.

The remaining part of the paper is structured as follows. Section 2 provides a review of the related literature. Section 3 introduces the data, and provides some descriptive evidence on the individual socio-economic traits associated with the Euroscepticism and on the pro-EU sentiment and political preferences in "treated" (i.e. Convergence Objective) and "untreated" regions. Section 4 shows the effect of EU transfers on public opinion and electoral approval for Eurosceptic parties. Section 5 concludes.

\section{Related literature}

This paper intersects several strands of literature. Broadly, the paper relates to the literature on the relationship between redistributive policies and political support; more specifically, drawing

\footnotetext{
${ }^{7}$ See Sala-i-Martin (1996), Boldrin and Canova (2001), Dall'Erba and Gallo (2008), Baker et al. (2010, 2012, 2013), Pellegrini et al. (2013), EU Commission (2016a, 2016b).

${ }^{8}$ The so called credit claiming phenomenon, Moravcsik (1994), Mayhew (1974).

${ }^{9}$ See Horeth (1999), McGraw (1991), Hobolt and Tilley (2014).

${ }^{10}$ FT May 17, 2016 "Cornwall's Brexit backers show that money cannot buy EU love"; The Economist Jun 302016, " I owe EU".
} 
upon the extensive literature on the impact of regional transfers within the EU, it assesses their effects on EU perception and political support for European integration. Finally, the paper also touches upon the literature that investigating the determinants of support/aversion toward the EU, both in terms of public opinion and electoral outcomes.

An extensive body of literature, mainly in political sciences, has examined the socioeconomic and cultural factors that shape the public attitude toward the EU and the trust in its institutions. ${ }^{11}$ In particular, some contributions have investigated whether the economic benefits from EU membership influence public support for European integration (Gabel, 1998; Gabel and Palmer, 1995). ${ }^{12}$ However, as regards the impact of the EU transfers, these works have provided inconclusive results. In a cross country analysis based on 1977-1988 Eurobarometer surveys, Eichenberg and Dalton (1993) find that countries' shares of the EU budget do not affect citizens' support for the EU. Their results have been questioned by Anderson and Reichert (1996), Hooghe and Marks (2005) and Diez Medrano (2003) who find a positive and statistically significant correlation between net transfers from the EU budget - or inclusion in the Convergence Objective program - and support for the EU. ${ }^{13}$ Gross and Debus (2018) focus on the political supply of pro/anti-EU positions to show that sub-national parties established in regions that receive more funds show a more favourable stance regarding the European integration. This evidence has been challenged by recent studies examining the results of the Brexit referendum: in particular, Fidrmuc et al. (2016) do not find any significant effect of EU Cohesion Policy on the propensity to vote for staying in the EU. ${ }^{14}$

A shared problem of the above-mentioned studies is that they cannot pin down the causal effect of EU transfers on attitudes toward the EU and produce estimates that are likely to prone to omitted variable bias and reverse causality problems. Indeed, the ability to obtain more funding from the EU budget (or more net transfers) depends on a series of institutional variables at regional and national level that are in turn related to the public attitude toward the EU. Similar considerations apply when analysing the effects of some specific programme: the eligibility rules

\footnotetext{
11 The literature has identified several socio-economic traits relevant to characterize EU supporters and opponents: higher educational attainment and higher skills have been found to lead to greater support of European integration (e.g., Gabel and Palmer, 1995, Anderson and Reichert, 1996, Gabel 1998, McLaren 2002, Hoogh and Marks, 2005, Dustman et al. 2017, Frieden 2017). Cultural traits, national identity, political partisanship, national (and regional) attitudes are important dimension affecting EU support: Inglehart, Rabier, and Reif 1991, Gabel, 1998, Hoogh and Marks, 2005. Some authors highglight the role of national and regional macroeconomic conditions in influencing public opinion on the EU and in raising consensus for Eurosceptic parties, especially after the EU debt crisis (Guiso et al. 2017, 2018, van Erkel et al. 2016, Frieden, 2016, Biancotti et al. 2017, Hobolt and de Vries, 2016, Kalbhenn and Stracca, 2015, Foster and Frieden, 2017, Schuman Report on Europe, 2013, Ringlerova, 2015, Frieden and Walter, 2017). More recently, the poor handling of the refugee crisis has also contributed to jeopardize the trust in the EU institutions (Guiraudon, 2017, Börzel and Risse, 2018).

${ }^{12}$ All these studies hinge on a theoretical explanation of the degree of support for the EU, known as the utilitarian appraisals of integrative policy (Gabel, 1998). In this framework "citizens in different socioeconomic situations experience different costs and benefits from integrative policy; these differences in economic welfare shape their attitudes toward integration; and consequently, that citizens' support for integration is positively related to their welfare gains from integrative policy" (Gabel and Palmer, 1995).

${ }^{13}$ Importantly, as compared to Eichenberg and Dalton (1993) the later studies exploit more recent surveys, that cover the years in which the European Cohesion and Structural Fund Programs were in place.

${ }^{14}$ On the socio-economic determinants of the Brexit referendum see Becker et al. (2017) and Colantone and Stanig (2018).
} 
that determine inclusion in the programme are usually related to specific individual, national or sub-national characteristics that are not independent from factors that influence both the public opinion and electoral outcomes.

To the best of our knowledge, this paper is the first to exploit exogenous variation in transfers in order to provide an estimate of the causal effect of EU funds on EU perception and Eurosceptical vote. Our identification strategy is inspired by the literature evaluating the effectiveness of the EU Cohesion Policy in fostering development in lower-income regions, a longtime debated issue in the literature. ${ }^{15}$ In particular, we draw from Becker et al. (2010), that implement a regression discontinuity design analysis which exploits the allocation rules of EU regional funds to trace out the effect of transfer across regions; they identify a positive causal effect of EU funding on regional GDP growth. ${ }^{16}$

We exploit an analogous identification strategy to answer a novel and relevant question which matters even in the absence of clear cut effects on growth and unemployment: what is the effect of EU transfers on public support for European integration? More precisely, we estimate the change in attitude toward the EU which can be attributed to funds transferred by the Cohesion Policy, abstracting from any economic effect of the policy. In other words, we do not enter the debate of whether the EU regional policy is cost-effective or even economically relevant.

Our work strongly relates to the behavioural economics and political science literature on reciprocity and on the support-buying effect of public transfers. In this framework, public transfers are envisioned to increase support for the government among the beneficiaries. Similar conclusions are reached by rational-vote theories. Empirically, these predictions have been confirmed by the seminal work by Levitt and Snyder (1997), which studies the relationship between spending and political outcomes in the US. Similar results are reiterated both in the US and in less developed countries (Chen, 2008, 2013; Manacorda et al., 2011). Overall, the existing empirical literature supports the prediction that transfers can buy political support.

We provide novel insights to the literature on vote-buying. First, our work represents the first attempt to investigate vote-buying effect of transfers in the EU context. The complexity of the European institutional framework, characterized by multiple layers of government, could blur the

\footnotetext{
${ }^{15}$ The first attempts to detect an effect of EU transfers on regional growth did not provide conclusive evidence: some authors diagnosed a failure of structural funds to generate regional growth (Sala-i-Martin,1996, Boldrin and Canova, 2001, Dall'Erba and Gallo, 2008), while others showed a positive correlation between Structural Funds Program and GDP-growth or agglomeration economies (see Midelfart-Knarvik and Overman, 2002; Beugelsdijk and Eijffinger, 2005; Cappelen, Castellacci, Fagerberg and Verspagen, 2003; Ederveen, Gorter, de Mooij and Nahuis, 2002; Ederveen, de Groot and Nahuis, 2006). Failure to properly account for the endogeneity of structural funds, both in terms of eligibility and expenditure, may explain such conflicting evidence.

${ }^{16}$ Becker et al. (2010) find a positive effect of EU funding on regional GDP growth, but no effect on employment growth, a result confirmed by Pellegrini et al. (2012) using EU Commission data. Accetturo et al. (2014) exploiting the setting find that EU transfers generate a deterioration of the endowments of trust and cooperation in subsidized regions.
} 
source of the transfer in the eyes of recipients, making our identification task more challenging. Second, we focus on an indirect transfer scheme, implying that it does not directly target individuals or households, but rather increases the regional government's budget to implement specific projects (e. g. infrastructural investments). The main consequence is that the transfer is less salient at the individual level, and makes it even more interesting to investigate if any effect on the individuals' opinions and voting behaviour can be detected.

\section{Data, institutional context and descriptive evidence}

\subsection{Data and institutional context}

Under the principle of Financial Solidarity, the EU Cohesion Policy provides regional level transfers according to a region's development and economic situation, measured by GDP per capita. EU Cohesion Policy transfers are delivered within three Objectives: Convergence Objective, to support less developed regions (GDP p.c. below $75 \%$ of the EU average); European Territorial Cooperation Objective, targeted at the more developed regions (GDP p.c. above $90 \%$ of the EU average); Regional Competitiveness and Employment Objective, aimed at supporting the inbetween regions (GDP p.c. between $75 \%$ and $90 \%$ of the EU average). ${ }^{17}$

With a budget of over 200 billion Euros, the Convergence Objective is one of the most sizeable intervention among the EU programs, absorbing alone about $35 \%$ of the EU budget. Hence, although most regions receive some EU transfers, those in the Convergence Objective receive much stronger support. In the years 2000-2014 the average per capita transfer for regions in the Convergence Objective was nearly $2100 €$, compared to around $180 €$ for the other regions. In other words, the EU Cohesion Policy allocation rule generates a discontinuity in the amount of funds received by regions whose GDP p.c. lies around the $75 \%$ of the EU average GDP p.c..

Budget, targets and funds allocation of the three Objectives are defined within programs of 6 years each. Since the early 2000s, namely the period covered by the ESS survey we exploit, we observe two full programs: first program, 2000-2006; second program, 2007-2014. ${ }^{18}$ The two programs overlap substantially. First, all regions included in the Convergence Objective during the 2007-2014 program were also included in the same Objective between 2000 and 2006. Second, only few regions falling within the Convergence Objective under the 2000-2006 program were excluded from the 2007-2014 program (see Figure A1 in the Appendix). These exceptions are mostly regions which were entitled to the Convergence Objective funds during the first program, even if their per capita GDP exceeded the $75 \%$ of the EU average. Only two regions are excluded from the 2007-

\footnotetext{
${ }^{17}$ It is hard to keep track with the names: this breakdown refers to the 2007-2014 period. Until 2006, the three Objectives were known as Objective 1, Objective 2 and Objective 3. Since 2014, the name "Objective" has been abandoned (despite the allocation rule persists). ${ }^{18}$ The official programming period goes from 2007 to 2013 . Yet, the last round of transfers was delivered in 2014. Hence, we prefer to refer to the 2007-2014 as a full programming period.
} 
2014 program because of economic reasons (i.e., their GDP p.c. no longer fell behind the new $75 \%$ threshold). ${ }^{19}$ Because of such persistence and given the long-term nature of the programs' under investigation, we think it is not sound to try to disentangle the effect of each funding program separately. We choose to consider the 2000-2006 and 2007-2014 programs jointly. It follows that our treatment variable is the amount of Cohesion Policy funds per capita, transferred to each region during the overall 2000-2014 period.

Figure 2 illustrates the distribution of Cohesion Policy funds across EU regions in per capita terms. Clearly, there is a great deal of variation in transfers across regions; yet, notably, regions included in the Convergence Objective in both programming periods receive substantially larger transfers as compared to the other ones (see Figure A1 in the Appendix for a map of regions included in the Convergence Objective).

\section{EU Cohesion Policy funds per capita (cumulative, 2000-2014)}

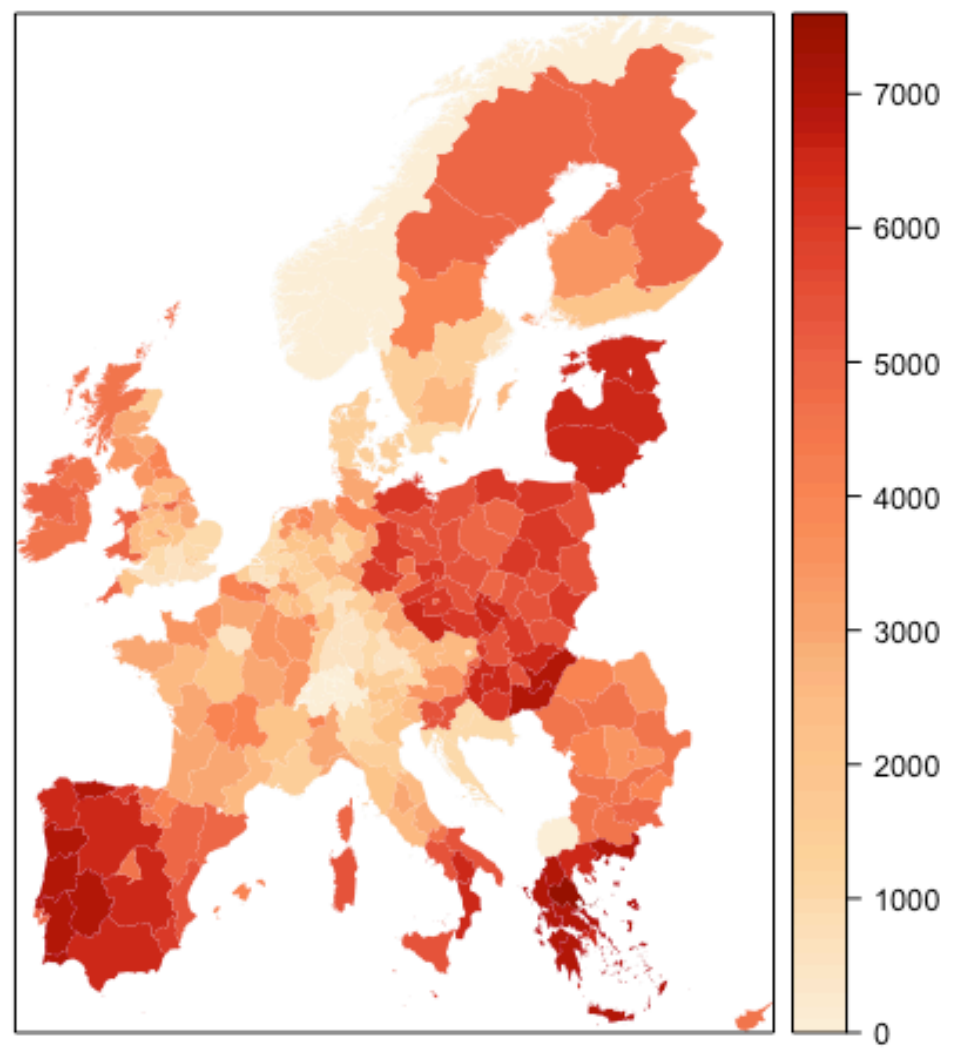

Figure 2

Source: European Commission

Our sample is composed by the EU15 regions. This choice has several reasons: first, the accession of new member states occurred in the middle of the period considered in our analysis

\footnotetext{
${ }^{19}$ Up until 2007 the Convergence Objective also covered categories of "special" regions: the seven "most remote regions"; areas in Sweden and Finland, because of the very low population density; Northern Ireland, which receives special Community assistance to promote reconciliation between the communities and the emergence of a stable and peaceful society.
} 
(mainly in 2004 and in 2007); second, most of the new regions where included in the Convergence Objective, with basically no variability within-country; third, public attitudes toward the EU in new member states have followed very peculiar dynamics. Indeed, starting from extremely high and positive levels at the moment of accession, public support has typically converged toward the levels prevailing in the other member states (Biancotti et al. 2017). All these factors suggest that by focusing on the EU15 we can rely on a more homogeneous group, which is important for the assumptions behind our identification strategy to hold true.

We draw from several data sources and exploit information both at the individual and at the regional level. ${ }^{20}$ Household-level information come from the European Social Survey (ESS). The survey, funded by the European Commission, the European Science Foundation and several national partners, 'has been mapping long-term attitudinal and behavioural changes in Europe's social, political and moral climate' since 2002 and is carried out every two years. At the time of writing this paper, data for seven rounds were available, up to 2014. The number of countries included varies depending on the wave. We consider only countries that were already part of the EU in 2000 (EU15), the starting year of the first EU programming period that we analyse. We exclude from the EU15 sample only Greece and Luxembourg, for which no information on individual characteristics is available in the ESS after 2010. The final sample consists of the NUTS 2 level regions of 13 countries: Austria, Belgium, Denmark, Finland, France, Germany, Ireland, Italy, the Netherlands, Portugal, Spain, Sweden and the United Kingdom; 28 regions were always supported by the Convergence Objective throughout the period 2000-2014, while 80 never received funding.

We measure attitudes toward EU integration by exploiting the following question from the ESS survey: "Now thinking about the European Union, some say European unification should go further. Others say it has already gone too far. Using this card, what number on the scale best describes your position?". The scale is between 0 and 10, with 0 labelled as "Unification has already gone too far" and 10 labelled as "Unification should go further".

To understand how the individual attitude towards the EU translates into electoral outcomes, we match the information about the political preferences expressed by the respondents of the ESS with the actual platforms of the political party they support. ${ }^{21}$ Compared to sentiment indicators, the measures based on matches between individual preferences and parties' positions are

\footnotetext{
20 The reference classification used to define a region is the Nomenclature of Territorial Units for Statistics (NUTS). The EU regional policy is defined at the NUTS 2 level (population between 800'000 and 3 millions).

${ }^{21}$ We capture the individual political party preference exploiting the following ESS question "Is there a particular political party you feel closer to than all the other parties? Which one?". Prime facie, another question in the ESS seems more related to the individual voting attitude: "Which party did you vote in the last national election?".
} 
more sensitive to a supply-side component, since individual attitudes are mediated by the political platforms offered by existing parties in a given moment and location (Guiso et al. 2017).

Party-level information on the orientation toward the EU integration and the immigration policy are based on the Chapel Hill Expert Survey (CHES). CHES provides an assessment of political party positions along different dimensions, several of which related to European integration. The survey has been conducted in 1999, 2002, 2006, 2010 and 2014. For the 2014 survey, 337 experts evaluated 268 parties in all EU countries. Party stances on international trade are not included in the CHES dataset, and also other sources, like the Manifesto Database Project, provide very poor information along this dimension. ${ }^{22}$ To obtain reliable proxies for the trade stance of parties, we look at actual votes on international trade casted by members of the European parliament (MEPs) elected in the $6^{\text {th }}, 7^{\text {th }}$ and $8^{\text {th }}$ term (from 2004 to 2017) which are also linked to specific national parties. The database of MEP voting behaviour has been provided by VoteWatch Europe ${ }^{23}$ and allows us to retrieve a direct assessment of parties' stance regarding protectionism and free trade based on their actual behaviour in the legislative process, instead of relying on indirect assessment.

The political parties' characteristics in our sample of 13 European countries suggest that the overall political orientation of a party (left/right position on a scale between 0 and 10) correlates both with the pro-EU and with the pro-trade stance in a similar way: Panels A and B of Figure 3 show well-defined hump-shaped correlations, meaning that far left and far right parties have similar Eurosceptic and anti-trade positions. On the other hand, when considering pro/antiimmigration stance, Figure 3, Panel $\mathrm{C}$ shows that parties divide along more traditional lines, with the Left in favour of permissive immigration policies and the Right supporting restrictive ones.

Summing up, our dataset is constructed as follows: for every respondent of the ESS in each one of the $13 \mathrm{EU}$ countries of our sample, we observe the NUTS 2 region in which he/she resides as well as the party which he/she feels closer to. By exploiting the residence information, we tie each ESS respondent to European Commission records on EU regional policy eligibility and actual allocated transfers, in euro, both under the first and second programming period. Additionally, we

\footnotetext{
${ }^{22}$ The Manifesto Project Database formally includes measures of the parties' support for protectionist and liberalisation policies based on their political manifestos. However, as shown by Biancotti et al. (2017), these scores are available only for a small set of parties and they show very limited variability. Moreover, these measures turn out to be unrelated with the overall left-right party position, while we expect radical parties (both far-right and far-left) to be markedly anti-trade.

${ }^{23}$ The index is based on a selection of 10 votes for each Parliamentary term. The votes have been selected according to the following set of requirements: a) geographical diversity: the votes are related to trade relations with different countries; b) sectoral diversity: the votes include trade agreements affecting different economic sectors; c) even distribution: controversial votes are included, as well as consensual votes; d) intragroup representation: some of the votes highlight divisions within certain political groups. After the selection of the votes, the parties voting in favor of a free trade proposal were assigned 1 point, whereas the ones opposing it received - 1 point. Similarly, parties opposing a protectionist proposal were assigned 1 point, whereas the parties supporting it received -1 point. In both cases, no points are assigned to the parties abstaining. In case of divisions within a party, the positions of the majority of MEPs belonging to that party was considered. The parties have been distributed across a scale ranging from 10 (maximum support for free trade) to -10 (maximum opposition to free trade). Then, the variable has been rescaled to the [0,10] interval to match the other variables' definition.
} 
tie each party favoured by ESS respondents to information on its stance on migration and the EU as contained in Chapel Hill Expert Survey (CHES), as well as its stance on trade according to voting records of the European Parliament.

Figure 3

\section{Parties' left-right positions and their stances on EU, trade and immigration}
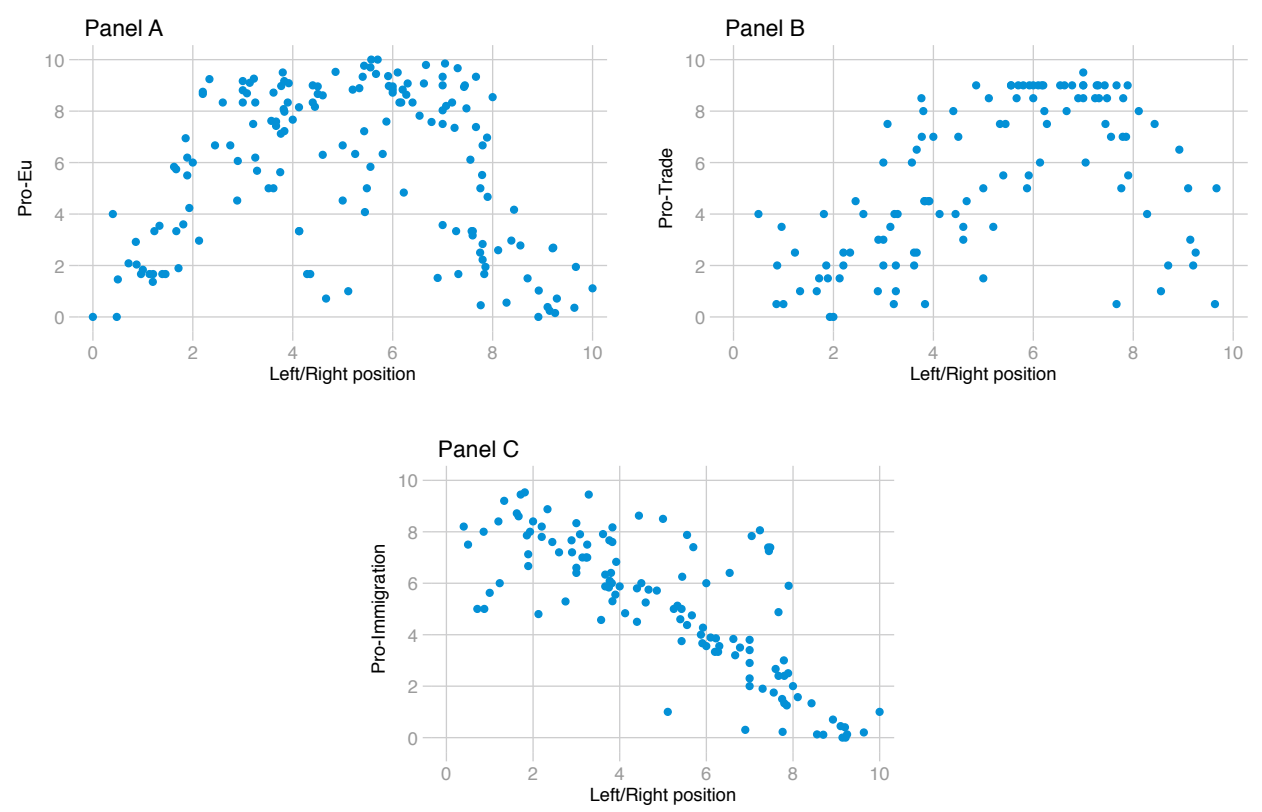

Each observation represents a political party active in the period 2004-2014 in the 13 countries of our sample. For each party, we report the most updated information on its stance, so that around $70 \%$ of the parties in the sample have been evaluated in 2014. Panel B considers only parties represented in the European parliament.

\subsection{Descriptive evidence}

First, we exploit individual information from the ESS survey to investigate how socio-economic characteristics are associated with the EU sentiment and the political support of anti-EU parties. These descriptive analyses are meant to provide a flavour of the main traits associated with Eurosceptical positions in our context and, by showing similar patterns to those previously unveiled by the literature, allow us to validate our measures of Euroscepticism. Figure 4 depicts the coefficients of multivariate regressions that show how pro-EU sentiment correlates with different individual socio-economic traits in regions that over the 2000-2014 period were included in the Convergence Objective (Funded regions) and those who were not (Not Funded regions). ${ }^{24}$

\footnotetext{
${ }^{24}$ For the sake of comparability, we exclude from the descriptive analysis the few regions that are included in the Convergence Objective only during one of the two programs.
} 
In general, opposition to the EU appears stronger among low-skill workers, individuals with lower educational attainment, those with income perceived to be insufficient to meet family's needs, ${ }^{25}$ and those spending large amounts of time watching entertainment TV.

Figure 4

\section{Support for European integration: conditional correlations with individual characteristics} (2012-2014 ESS data)

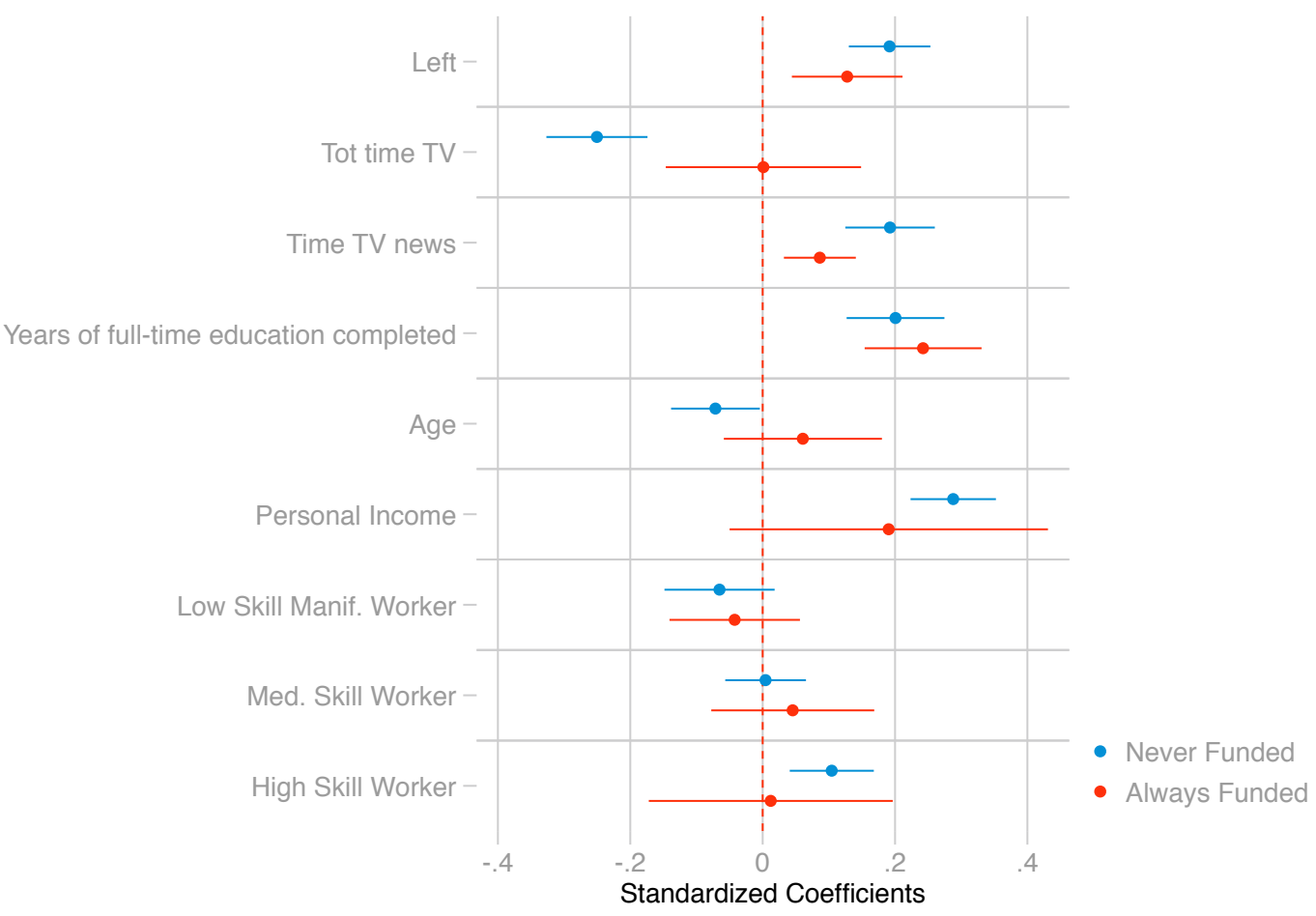

Note: Always funded regions are defined as regions obtaining Convergence Objective funds during both Programs. The multivariate regression includes year fixed effects. We also include regional real income per capita level, a proxy for the regional economic cycle (3-year change in regional income), gender, retirement status and other occupational conditions (e.g. housework, under education, non-reported occupation). 95\% Confidence intervals. Weighted regressions with sampling weights.

Notably, among low-skill workers ${ }^{26}$ those employed in the manufacturing sector exhibit a more negative attitude toward the EU compared to similarly skilled individuals, but engaged in non-manufacturing activities, which are the reference group of the regressions. This is consistent with the idea that low-skill workers in manufacturing have suffered the most from the negative effects of external shocks (in particular from trade liberalisation), which might have contributed to deplete their goodwill toward economic integration with other European countries. These characteristics are similar to those identified by previous studies investigating the

\footnotetext{
${ }^{25}$ The variable personal income used in the regression analyses refers to the self-assessed personal economic condition and takes four possible values, ranging from "very difficult living on present income" to "living comfortably on present income".

${ }^{26}$ We define as low skill workers all the individuals engaged in an occupation in the classes $6,7,8$ and 9 of the ISCO-08 classification, corresponding to the elementary and skilled-manual activities in the official ILO taxonomy. Then we distinguish between low skill workers employed in manufacturing activities and low skill workers employed in non-manufacturing ones. The latter category is used as reference group in the regressions.
} 
heterogeneous impact of globalisation (Autor et al, 2014; Antràs et al., 2017), or the appeal of antiestablishment rhetoric (Durante et al., 2015; Guiso et al., 2017). Using individual ESS data, Biancotti et al. (2017) compare the preferences for pro-EU parties results with those for pro-trade and pro-immigration parties, finding that the correlations are very similar to those shown in Figure 4. Conditional correlations estimated for ESS respondents of Convergence Objective regions and those living in other areas appear very similar to each other, with the only exception of TV time; point estimates for Convergence Objective regions are less precisely estimated because the sample size is considerably smaller.

Figure 5 provides a first descriptive evidence of different attitudes towards the EU integration between Convergence Objective regions and the other ones, by comparing regions regions always supported by the Convergence Objective throughout the period 2000-2014 and regions that never received funding.

Figure 5

\section{Average support for European integration in funded and non-funded regions}

a) Sentiment: average of self-reported scores on a $0-10$ scale; 2012-2014 averages ${ }^{a}$

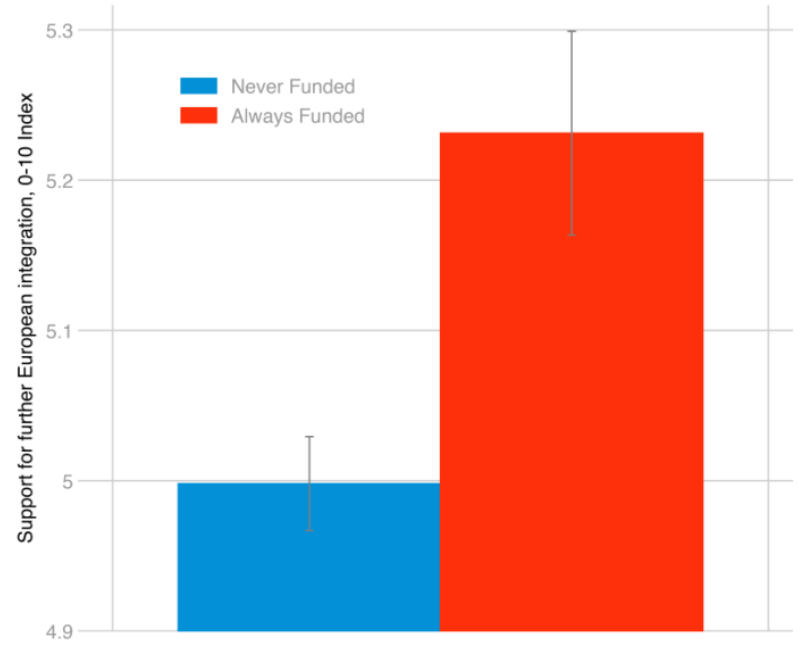

b) Political preferences: share of individuals that feel close to anti-EU parties; 2012-2014 averages

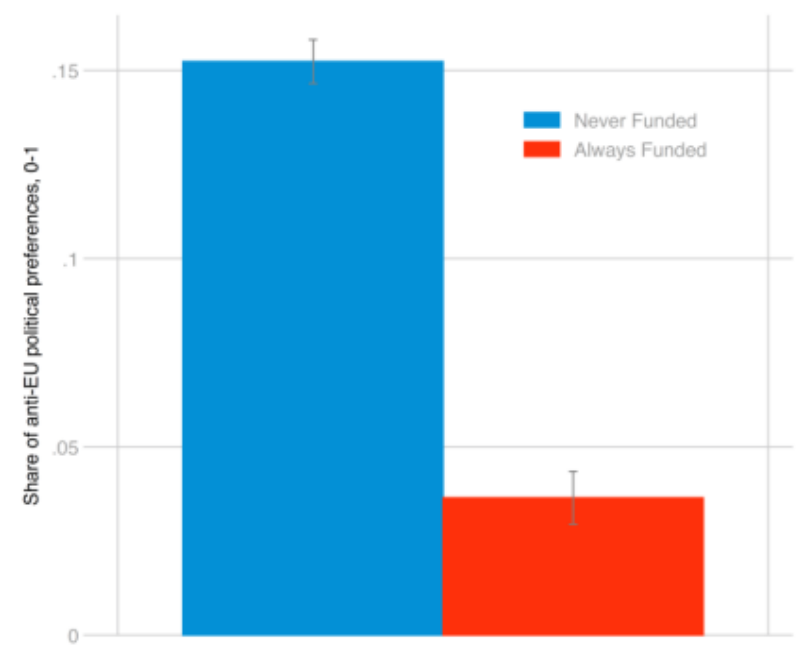

a) For Italy only 2012 figures, as it was not included in the ESS survey in 2014.

At the end of the period considered, on average the support for further European integration was significantly higher in regions that received regular transfers under the Convergence Objective (see: Figure 5, panel a). Results are similar looking directly to political preferences (Figure 5, panel b): individuals living in Convergence Objective regions were less likely to choose parties with an anti-EU stance. ${ }^{27}$ Obviously many confounding factors could be driving

${ }^{27}$ Political parties classified as anti-EU are those with a score strictly below 4 in the 0-10 rating scale of the Chapel Hill Expert Survey. 
these results, first and foremost the fact that only less developed regions are included in the Convergence Objective. Nevertheless, even after controlling for various individual and macroeconomic characteristics, living in regions heavily funded by the EU regional policy is associated with a more positive attitude toward the EU and a lower propensity to prefer Eurosceptic parties (see Table A1 in the Appendix). This result is in line with the findings in Diez Medrano, 2003 and in Hooghe and Marks, 2005. Notably, both size and significance of the effect are very sensitive to the chosen specification and a-priori it is not clear which should be the correct one, as problems of omitted variables, reverse causality and bad controls arise depending on the case. These endogeneity issues, partially related to the selection bias in the allocation of the funds, affect the OLS analyses so far implemented in the literature and have to be tackled to single out the causal relations of interest.

\section{Empirical strategy}

We exploit the eligibility rule that determines the inclusion in the Convergence Objective to identify the causal effect of Cohesion Policy transfers on the attitude toward the EU and on political preferences for pro (or anti)-EU parties. The regression discontinuity design (RDD) strategy relies on the following exogenous variation in transfers: regions whose income per capita falls just below the $75 \%$ of EU average are included in the Convergence Objective, thus being entitled to much larger transfers compared to regions whose GDP per capita is just above the $75 \%$ threshold. Notably, some regions, albeit exceeding the $75 \%$ threshold, still benefitted from Convergence Objective funds during the first program considered (2000-'06) giving rise to a Fuzzy RD design framework.

Our running variable is GDP per capita relative to the EU average in the pre-treatment period and our cut-off is located at the $75 \%$. Since we consider the two programs as a joint one, we exploit the eligibility rule at the beginning of the time-span of interest and we use as running variable the relative GDP per capita estimated by the European Commission in $1999 .{ }^{28}$ Indeed, Figure A2 in Appendix shows that pre-2000 eligibility rule largely determines the probability of receiving Convergence Objective status both for the first and the second program.For our estimates to be unbiased it is required that, a) in the neighborhood of the cut-off, the distribution of all observed and unobserved characteristics of the regions, but for the funds, is continuous and b) regions cannot manipulate their assignment variable. As to the former assumption, Becker et al. (2010) and Accetturo et al. (2014) show that demographic and geographical characteristics, infrastructure, population density, education and employment are balanced around this threshold

\footnotetext{
${ }^{28}$ In order to evaluate the eligibility for the different Regional programs the European Commission compute the GDP per capita of EU NUTS2 regions as the average of the most recent three years of available data, before the start of the programming period (i.e. 19961998 for the 2000-2006 program). In our analysis we employ the official estimates elaborated by the European Commission in 1999 , that exclude posterior data revisions.
} 
at baseline; moreover, to our knowledge there is no other policy that makes use of the same cut-off to discriminate between regions. As to the latter assumption, we, and the literature before us, ${ }^{29}$ argue that it is very unlikely for the regions to manage to manipulate their declared GDP per capita in order to settle just below the $75 \%$ cut-off. In fact, such reference value is computed by the European Commission based on the figures for the last three years of data available at the time when the deliberation over the funds' assignment is made, and it is therefore hard to guess with precision ex-ante.

Figure 6

First Stage: per capita cumulated regional transfers and GDP per Capita (2000-2014)

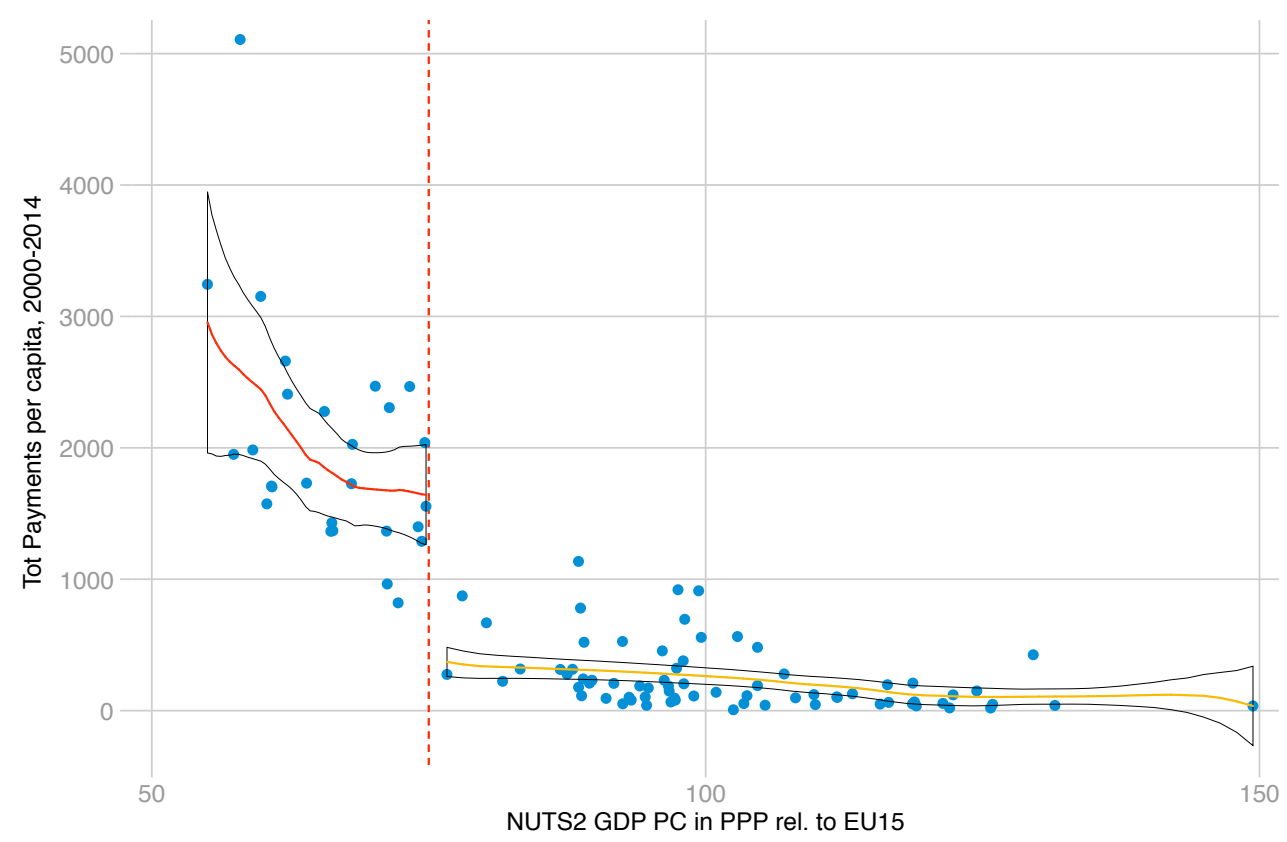

Note: Values on the $\mathrm{x}$-axis are those in the official indexing computed by the European Commission in 1999 for the 2000-2006 program.

Figure 6 illustrates our first stage relation and solves a major concern, as regions above the cut-off are either entitled to funding from other components of the EU regional policy or partially financed under the Convergence Objective itself (i.e. the above-mentioned "special regions"). The Convergence Objective allocation rule actually generates an exogenous variation in the amount of EU regional policy funds received by each region at the $75 \%$ threshold, which we can exploit in order to identify the causal effect of interest. As shown in the Appendix, the discontinuity at the threshold is even more pronounced considering the ratio of funding over regional GDP, as compared to per-capita transfers (Figure A3 and A4). The two key assumptions of our identification strategies are confirmed: first the Convergence Objective delivers substantially higher transfers relative the other EU regional policy programs; second, and most importantly, the

\footnotetext{
${ }^{29}$ See Becker et al. (2010, 2013) and Pellegrini (2012).
} 
cumulated funds received over the 2000-2014 period indeed changes discontinuously at the $75 \%$ threshold.

We are interested in quantifying the effect on sentiment and electoral outcomes of EU Regional policy transfers; a natural way to think about our "treatment" is to define it continuously, as the total per capita Cohesion Policy funds received by each region for the full 2000-2014 period. As mentioned, the amount of funds received cannot be considered exogenous. However, the Convergence Objective eligibility rule can serve as an instrument for the total EU Cohesion Policy transfers received by each region, allowing us to identify the funds causal effect. This strategy exploits the very same exogenous variation of a fuzzy RD regressions with binary treatment (Becker et al. 2010) and allows us to deal with the presence of "special" regions, which do not meet the eligibility rule but receive Convergence Objective funds only for half of the total time-span of interest. Moreover, under linearity assumption these estimates provide us with a measure of the local effect of each additional euro of EU transfers on pro-EU attitude-changing and vote buying.

As an alternative approach, we consider the binary treatment of having or not Convergence Objective status to estimate the difference in sentiment and electoral outcomes between regions just above and below the $75 \%$ threshold. A caveat with this approach is how to deal with "special" regions. Since special regions, namely those not complying with the cut-off rule during the first programming period, received Convergence Objective payments only during the first programming period they cannot be categorized neither as "Convergence Objective", i.e. treated, nor as "NonConvergence Objective", i.e. non-treated. We deal with this issue by excluding them from the sample when estimate the effect of the binary treatment. ${ }^{30}$

Our main outcomes of interest are: first, the attitude towards the EU integration; second, electoral outcomes as proxied by political preferences and in particular, support for anti-EU parties. When looking at citizens' attitude we consider the shifts of the distribution means, but we also pay attention to the mass on the left tail of the distribution, which corresponds to the size of the Eurosceptic group. We measure outcomes at the end of the second programming period, which coincides with the last publicly available round of the ESS survey at the time of writing this paper. Since the second program officially ends in 2013, but payments were received until 2014, we consider 2012-2014 averages. This choice also reduces noise related to year-specific idiosyncratic factors and allows us to increase our sample size including also Italian regions, observed in the ESS only until 2012 .

\footnotetext{
30 As the main reason for implementing a fuzzy RDD was the presence of the "special" regions dropping them from the sample mechanically makes our setting abiding to the assumptions of a sharp RDD.
} 


\section{Results}

\subsection{Effects on pro-EU attitude and political appraisal: graphical analysis}

In what follows, we present our baseline results. Across all specifications, individuals' attitude toward the EU at the end of the second programming period was significantly more positive in those regions which had been receiving more Cohesion funds.

Figure 7 and 8 illustrate our main results graphically: we plot the average attitude toward the EU integration (Figure 7) and anti-EU political preference (Figure 8), at the NUTS 2 level in 2014 over region $i$ 's p.c. GDP in PPS relative to the EU average, namely our running variable. Figure 7 shows that the attitude toward the European integration drops at the $75 \%$ threshold, implying that, ceteris paribus, regions to the left of the $75 \%$ cut-off show more positive sentiment towards the European Union compared to those just to the right. Building on this evidence, Figure 8 shows that differences in sentiment toward the EU translate in actual differences in political preferences: indeed, the share of individuals that opt for an anti-EU party is much larger in those regions that happen to be just to the right of the $75 \%$ threshold. ${ }^{31}$

By contrast, as shown in Figure 9 and Figure 10, individuals living in regions with GDP per capita in PPP close to the $75 \%$-threshold are equally likely to vote for anti-trade and antiimmigration parties. Since populistic parties tend to be voted by individuals with broad antiestablishment attitudes (anti-EU, anti-trade, anti-immigration), the fact that we only observe an effect on anti-EU parties vote reassures us that we are not simply capturing some inherent difference in the pool of voters between treated and non-treated regions around the cut-off.

\footnotetext{
${ }^{31}$ The estimated functions are a Epanechnikov kernel function of degree 0 and the blurred areas represent $95 \%$ confidence intervals. The results are not altered by the choice of the function. Observations at the right of the $75 \%$ cut-off include "special regions", hence the estimated ITT effect is likely to provide conservative estimates of the actual effects.
} 
Figure 7

EU sentiment and pre-2000 relative GDP per capita in "treated" and "untreated" regions

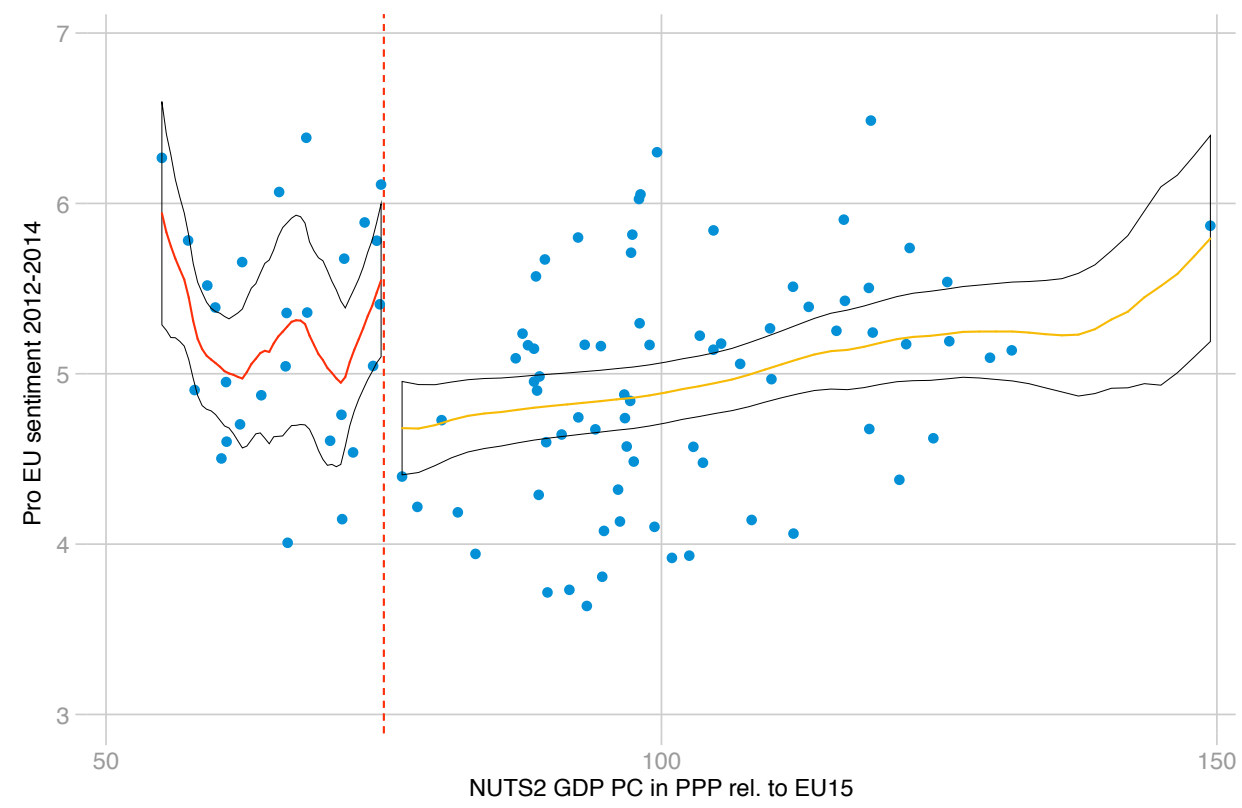

Note: Confidence intervals at the $95 \%$ significance level. Values on the x-axis are those in the official indexing computed by the European Commission in 1999 for the 2000-2006 program. The red dashed vertical line represents the 75\% of the EU average p.c GDP in PPS as defined by the EU commission for the p.p. 2000-2006.

Figure 8

Preferences for anti-EU parties and Convergence Objective (2000-2006) allocation rule:

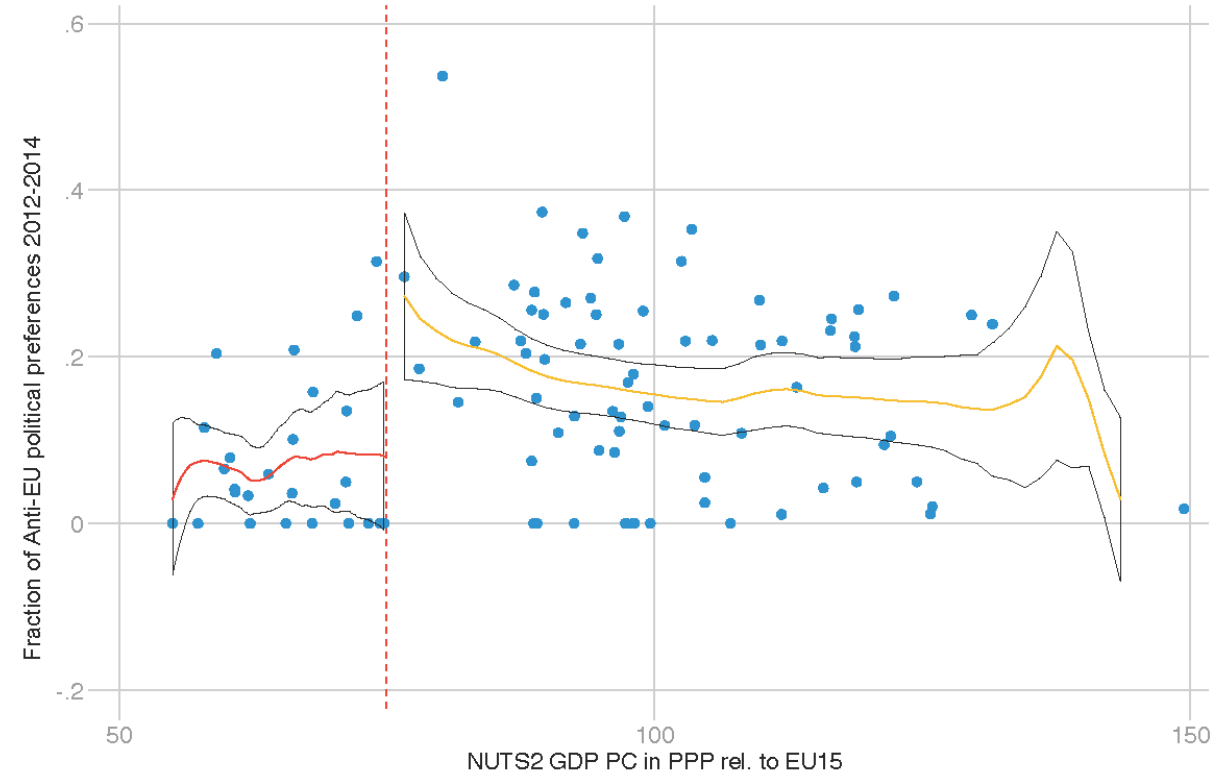

Note: Confidence intervals at the $95 \%$ significance level. Values on the $x$-axis are those in the official indexing computed by the European Commission in 1999 for the 2000-2006 program. The red dashed vertical line represents the 75\%-rule, namely 75\% of the EU average GDP per capita in PPS as defined by the EU commission for the programming period 2000-2006. 
Figure 9

Preferences for anti-trade parties and Convergence Objective (2012-2014) allocation rule

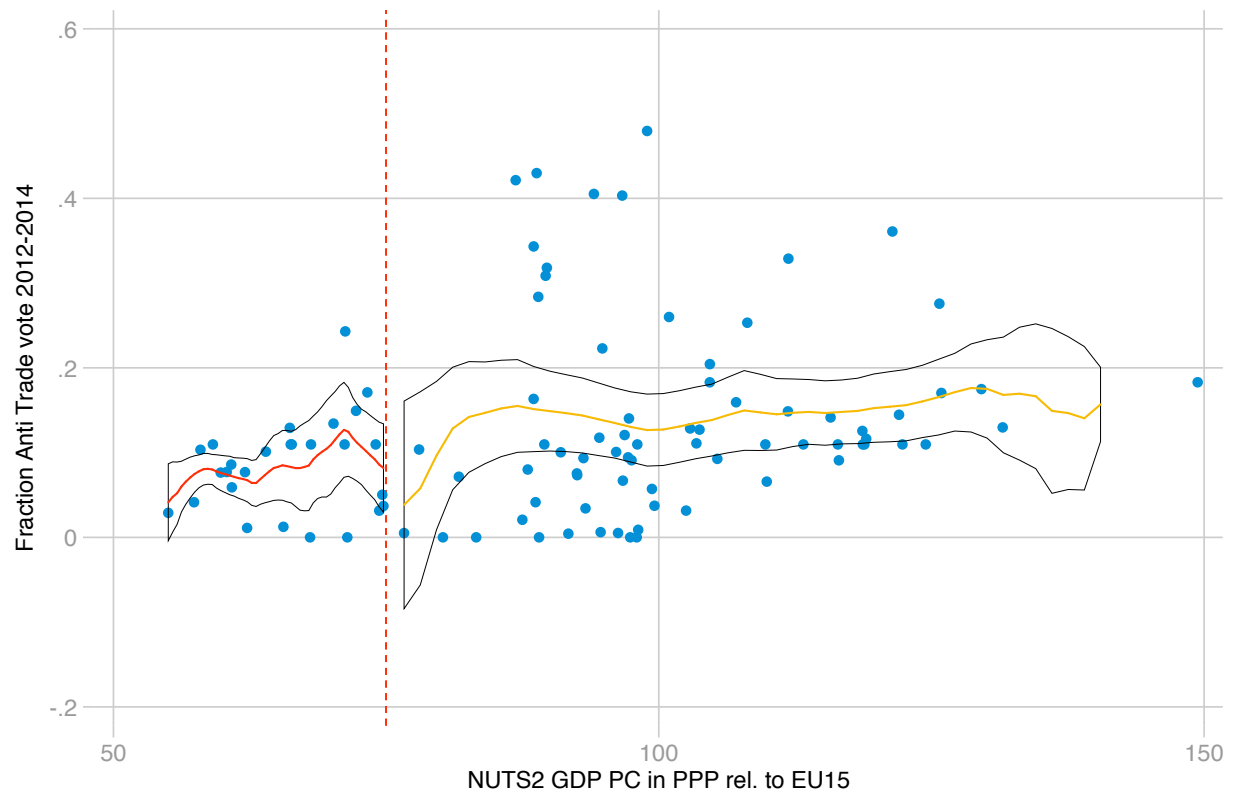

Note: Confidence intervals at the 95\% significance level. The Convergence Objective Assignment rule is based on the indexing used by the European Commission. According to EU law, such index is constructed by comparing the 3-year-average GDP per capita at the regional level relative to the 3-year-EU15 average before the programming period starts (2000).

Figure 10

Preferences for anti-immigration parties and Convergence Objective (2012-2014) allocation rule

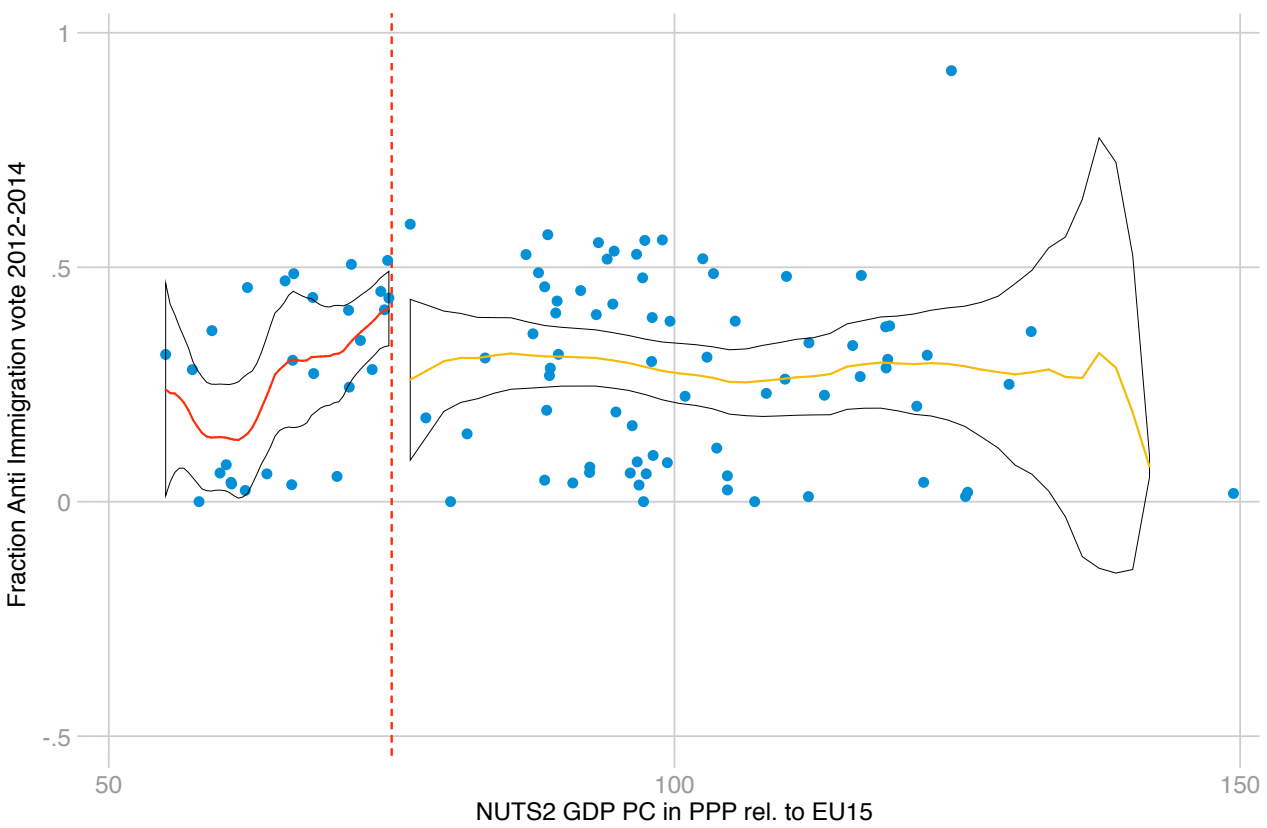

Note: Confidence intervals at the 95\% significance level. The Convergence Objective Assignment rule is based on the indexing used by the European Commission. According to EU law, such index is constructed by comparing the 3-year-average GDP per capita at the regional level relative to the 3-year-EU15 average before the programming period starts (2000). 


\subsection{Effects on pro-EU attitude and political appraisal: regression analysis}

We estimate two regression models. First, a fuzzy RDD where the independent variable is the cumulated funds received under the EU Cohesion Policy by each region over the 2000-2014 period. A fuzzy RDD is conceptually similar to an Instrumental Variable approach where the instrument is the eligibility rule (i.e. the $75 \%$ threshold). Consistently, we estimate:

$$
Y_{i}^{a}=a+b \text { TotEURegioFund } s_{i}+f\left(X_{i}\right)+u_{i}
$$

where on the left-hand side, $Y_{i}^{a}$ is the average individual specific outcome variable of interest measured at the end of the program in region $i$ while on the right-hand side, $X_{i}$ is our running variable (ratio between region $i$ 's GDP per capita in PPS and the EU average in the pre-treatment period) and $u_{i}$ is the error term. TotEURegioFunds $s_{i}$, the total EU Cohesion Policy funds received by each region, is instrumented by the predicted values of the following First Stage regression:

$$
\text { TotEURegioFund } s_{i}=\alpha+\beta \text { Rule }_{i}+f\left(X_{i}\right)+\varepsilon_{i} .
$$

From Figure 7, we see that the instrument satisfies the relevance condition; under the RDD assumptions, it also satisfy the exclusion restriction. Assuming linearity in the relationship, such specification allows us to estimate directly the vote- and sentiment- buying effect of each additional euro spent in the EU Cohesion Policy at the 75\%-cutoff (LATE).

Second, we estimate the effect of the Convergence Objective status on attitude towards the EU and political preferences, that is we quantify the overall effect of the policy. To do so we drop the "special regions" from the sample and we estimate the following sharp RD model:

$$
Y_{i}^{a}=a+b R u l e_{i}+f\left(X_{i}\right)+u_{i}
$$

Rule $_{i}$ is a dummy taking value one if region $i$ meets the $75 \%$ assignment rule, $\alpha$ is an unknown parameter and $\varepsilon_{i}$ is random noise.

In both estimations, we cluster standard errors at the national level. We repeat both the estimations including different order of polynomials in the running variable, $f\left(X_{i}\right){ }^{32}$ Notice that this implies that we lean toward the parametric approach as our preferred specification. The main reason is that, given the limited sample size, there is not a critical mass of data points around the

\footnotetext{
${ }^{32}$ As discussed in Robin, Zhu and Bloom (2012), this can be particularly important in situations where data that are very far from the cut-point are included in the analysis or in which there is nonlinearity in the relationship between the outcome and the assignment variable. On top of a linear specification, we run a linear specification that also includes an interaction term between our running variable and the treatment and a quadratic specification. According to the main specification tests (Lee and Lemieux (2010)), a simple linear model adequately depicts the relationship between our outcome and the running variable. Hence, we choose the linear specification as our baseline, considering it a more conservative choice. Other specifications are reported in Appendix Table A2 and A3.
} 
cut-off and hence a non-parametric approach is unlikely to have enough power to precisely estimate the effect at the cutoff.

In our baseline regressions we exclude observations falling in the upper and lower $5 \%$ of the (pre-treatment) per capita income distribution in order to enhance the comparability among the regions included in the sample and reduce the estimation influence of observations far away from the discontinuity point. The choice of this specific trimming level comes from trading off bias with precision of the estimates; following standard RDD validations, we show that results are substantially unaffected at larger tails' trimming levels. ${ }^{33}$ To minimize concerns related to regions' comparability around the $75 \%$ - cutoff, we include potential confounding factors as controls. ${ }^{34}$ Specifically, we control for population density, for whether the region has been recipient of EU regional policy programs before 2000 and for the share of individuals employed in agriculture, which control works as a proxy for the amount of EU Common Agricultural Policy (CAP) funds that a region receives. ${ }^{35}$

Results are summarized in Table 4, which reports both the estimations exploiting payments per capita that each region received during the 2000-2014 period (from column 1 to column 3) and the specification based on binary Convergence Objective status (column 4 to 6). ${ }^{36}$ In Columns 1 and 4 we estimate a basic model, linear in the running variable; in columns 2 and 5 we allow the estimated function's slope to change at the cut-off; and finally, in columns 3 and 6 we include the above-mentioned controls.

According to all the specifications Cohesion Policy funds have a positive and statistically significant effect on the attitude toward EU integration. The estimates based on the amount of per capita funding are consistent across the specifications. Taking the most flexible model as a benchmark (column 3), a $1000 €$ increase in the per capita funds received by a region over the 20002014 period improves individuals' attitude toward the EU by about 0.63 points, on a scale from 0 to 10, and reduces the share of Eurosceptic individuals by about 8 percentage points.

The estimates of the binary effect of falling or not into the Convergence Objective (columns 4-6) suggest that the inclusion in this program increases average sentiment toward the EU by 0.86 points, while it reduces the share of anti-EU by almost 11 p.p.. These figures are consistent with

\footnotetext{
33 See Appendix Table A4 and A5.

${ }^{34}$ In Froehlich (2007) " [...] observations to the left and right of the threshold differ in observed characteristics. [...] Accounting for these differences in covariates is important to reduce bias. In addition, accounting for covariates may also reduce variance."

${ }^{35}$ The CAP has always been a central element in the European institutional system, representing $71 \%$ of the EU budget in 1984 to $39 \%$ in 2013. In fact, the CAP implements a large system of subsidies that are also meant as development funds (in agriculture), and if those transfers were targeted to the less developed regions, this might have led to an over-estimation of the Convergence Funds effect (see Anderson and Reichert, 1996).

36 In section 4 we have defined as "sharp" RD the RD estimation over the sample which excludes special regions (i.e. regions included in the Converge Objective despite not complying with the cut-off rule).
} 
those estimated using the continuous treatment, considering that the estimated difference in per capita funding between Convergence Objective regions and non-Convergence Objective regions at the threshold amounts to about 1200-1300 euros. Given that the sample average of our pro-EU sentiment index is ca. 5 points, the estimated improvement in pro European Union sentiment due to the inclusion into the Convergence Objective is substantial, ranging between $14 \%$ and $17 \%$ at the end of the second programming period.

We now take a step forward and try to understand whether the European Cohesion funds have actually mitigated the rise of Eurosceptic parties in the EU. In other words, we ask whether the improved sentiment toward the European Union is also associated with a weaker support for anti-EU parties. In Table 5 we exploit information about ESS respondents' preferred parties, and we find that Cohesion Policy funding negatively affects the propensity to choose parties with a more negative stance toward European integration.

Table 4

RDD results: effect of EU funding on EU sentiment at the end of the program

\begin{tabular}{lccc|ccc}
\hline \multicolumn{1}{c}{ Treatment Var } & \multicolumn{3}{c}{ EU funds (1000 euro) } & \multicolumn{3}{c}{ Convergence Objective status } \\
\hline Outcome Var & $(1)$ & $(2)$ & $(3)$ & $(4)$ & $(5)$ & $(6)$ \\
\hline \hline Avg. EU sentiment & $0.560^{* * *}$ & $0.768^{* * *}$ & $0.630^{* *}$ & $0.839^{* *}$ & $1.036^{* * *}$ & $0.856^{* *}$ \\
& $(0.21)$ & $(0.196)$ & $(0.246)$ & $(0.382)$ & $(0.345)$ & $(0.328)$ \\
& & & & & & \\
& & & & & & \\
& $-0.054^{* *}$ & $-0.094^{* * *}$ & $-0.084^{* *}$ & -0.081 & $-0.121^{* * *}$ & $-0.107^{* *}$ \\
& $(0.027)$ & $(0.03)$ & $(0.037)$ & $(0.052)$ & $(0.044)$ & $(0.042)$ \\
& & & & & & \\
\hline Nhare of anti-EU & 98 & 98 & 95 & 84 & 84 & 83 \\
\hline \hline Model & linear & linear & linear & linear & linear & linear \\
Interaction & NO & YES & YES & NO & YES & YES \\
Controls & NO & NO & YES & NO & NO & YES \\
Trim & $5 \%$ & $5 \%$ & $5 \%$ & $5 \%$ & $5 \%$ & $5 \%$ \\
St. Errors & Cluster & Cluster & Cluster & Cluster & Cluster & Cluster \\
\hline \hline
\end{tabular}

Standard errors are clustered at the national levels. ${ }^{*} p<0.1 ;{ }^{* *} p<0.05 ; * * * p<0.01$. Average individual sentiment towards the EU ranges between $O$ (anti-EU) and 10 (pro-EU). Share of anti-EU is the share of individuals in the regions with a sentiment towards the EU lower or equal to 3. Outcome variables are 20122014 averages.

Table 5

RDD results: effect of EU funding on public support for anti-EU parties at the end of the programs 


\begin{tabular}{lccc|ccc}
\hline \multicolumn{1}{c}{ Treatment Var } & \multicolumn{3}{c}{ EU funds (1000 euro) } & \multicolumn{3}{c}{ Convergence Objective status } \\
\hline Outcome Var & $(1)$ & $(2)$ & $(3)$ & $(4)$ & $(5)$ & $(6)$ \\
\hline \hline Share of anti-EU & $-0.124^{* * *}$ & $-0.108^{* * *}$ & $-0.097^{* * *}$ & $-0.164^{* * *}$ & $-0.174^{* * *}$ & $-0.155^{* * *}$ \\
political & $(0.04)$ & $(0.04)$ & $(0.035)$ & $(0.053)$ & $(0.044)$ & $(0.048)$ \\
preferences & & & & & & \\
\hline N. Obs. & 98 & 98 & 95 & 84 & 84 & 83 \\
\hline \hline Model & linear & linear & linear & linear & linear & linear \\
Interaction & NO & YES & YES & NO & YES & YES \\
Controls & NO & NO & YES & NO & NO & YES \\
Trim & $5 \%$ & $5 \%$ & $5 \%$ & $5 \%$ & $5 \%$ & $5 \%$ \\
St. Errors & Cluster & Cluster & Cluster & Cluster & Cluster & Cluster \\
\hline \hline
\end{tabular}

Standard errors are clustered at the national levels. The share of anti-EU political preferences is the share of individuals in the regions who prefer a party with a negative stance towards the EU (score lower or equal to 3, on a 0-10 scale, source: $C H E S)$. Outcome variables are 2012-2014 averages.

${ }^{*} p<0.1 ;{ }^{* *} p<0.05 ;{ }^{* * *} p<0.01$.

A $1000 €$ increase in the per capita funds received by a region over the 2000-2014 period reduces the voters' support for anti-EU parties by 10 percentage points, according to our baseline specification. Again both the magnitude and the significance of the effects are confirmed by the sharp (binary) RD estimates.

Table 6

RDD results: effect of EU funding on political preferences

\begin{tabular}{|c|c|c|c|c|c|c|}
\hline \multirow[b]{2}{*}{ Outcome Var } & \multicolumn{3}{|c|}{ EU funds (1000 euro) } & \multicolumn{3}{|c|}{ Convergence Objective status } \\
\hline & Left/Right & $\begin{array}{c}\text { Share of } \\
\text { radical left } \\
\text { prefences }\end{array}$ & $\begin{array}{c}\text { Share of } \\
\text { radical right } \\
\text { prefences }\end{array}$ & Left/Right & $\begin{array}{l}\text { Share of } \\
\text { radical left } \\
\text { prefences }\end{array}$ & $\begin{array}{c}\text { Share of } \\
\text { radical right } \\
\text { prefences }\end{array}$ \\
\hline & (1) & $(2)$ & (3) & (4) & (5) & (6) \\
\hline & $\begin{array}{l}-0.600 * * \\
(0.281)\end{array}$ & $\begin{array}{r}0.017 \\
(0.033)\end{array}$ & $\begin{array}{l}-0.098 * * * \\
(0.028)\end{array}$ & $\begin{array}{c}-0.725 * \\
(0.434)\end{array}$ & $\begin{array}{r}0.060 \\
(0.043)\end{array}$ & $\begin{array}{l}-0.129 * * * \\
(0.045)\end{array}$ \\
\hline N. Obs. & 98 & 98 & 94 & 84 & 84 & 82 \\
\hline Model & linear & linear & linear & linear & linear & linear \\
\hline Interaction & NO & YES & YES & NO & YES & YES \\
\hline Controls & NO & YES & YES & NO & YES & YES \\
\hline Trim & $5 \%$ & $5 \%$ & $5 \%$ & $5 \%$ & $5 \%$ & $5 \%$ \\
\hline St. Errors & Cluster & Cluster & Cluster & Cluster & Cluster & Cluster \\
\hline
\end{tabular}

Standard errors are clustered at the national levels. ${ }^{*} p<0.1 ;{ }^{* *} p<0.05 ;{ }^{* * *} p<0.01$. The left/right placement refers to the average position of the individual favoured party in the region, on a scale from 0 to 10 (source: CHES). The share of radical left (right) preferences is the share of individuals in the regions who prefer a radical left (right) party, with a score on the left/right political spectrum (source: CHES) lower (higher) or equal to 2 (8). Outcome variables are 2012-2014 averages.

In Table 6 we dig deeper into the underlying political changes induced by the EU funding. Results suggest that the Cohesion Policy funds significantly reduce the consensus for far right parties. On the contrary our estimates show that far left parties marginally benefit from the funding, though effects are much smaller in magnitude and not precisely measured. These results 
contribute to qualify our evidence about the positive effect of $\mathrm{EU}$ funding on public support for pro-EU parties: far right parties are usually the most resolute opponents of European integration (see Figure 3 in panel A, section 3.1); thus it is possible that EU transfers, by promoting a positive perception of the European integration, have somewhat contributed to mitigate the rise of nationalistic platforms in funded regions.

\subsection{Heterogeneous effects and mechanism}

In the descriptive analysis we showed how individual level socio-economic characteristics play a relevant role in shaping citizens' attitude toward the EU. In this section, we assess whether Cohesion Policy effect on pro/anti-EU attitudes is homogenous among different social groups or whether it is driven by specific population subgroups.

Table 7

RDD results: effect of EU funding on different socio-economic groups of the population

\begin{tabular}{|c|c|c|c|c|c|c|c|c|}
\hline \multirow{3}{*}{$\begin{array}{l}\text { Treatment Var } \\
\text { Outcome Var }\end{array}$} & \multicolumn{4}{|c|}{ EU funds (1000 euro) } & \multicolumn{4}{|c|}{ Convergence Objective status } \\
\hline & \multicolumn{2}{|c|}{ Avg. EU sentiment } & \multicolumn{2}{|c|}{ Share of anti-EU } & \multicolumn{2}{|c|}{ Avg. EU sentiment } & \multicolumn{2}{|c|}{ Share of anti-EU } \\
\hline & Not Exp. & Exp. & Not Exp. & Exp. & Not Exp. & Exp. & Not Exp. & Exp. \\
\hline & $\begin{array}{c}0.891 * * * \\
(0.216)\end{array}$ & $\begin{array}{l}0.893^{* * *} \\
(0.299)\end{array}$ & $\begin{array}{l}-0.110^{* * *} \\
(0.034)\end{array}$ & $\begin{array}{l}-0.097 * * \\
(0.04)\end{array}$ & $\begin{array}{c}0.968^{* * *} \\
(0.317)\end{array}$ & $\begin{array}{l}1.018^{* *} \\
(0.423)\end{array}$ & $\begin{array}{l}-0.112 * * \\
(0.05)\end{array}$ & $\begin{array}{l}-0.097 * \\
(0.056)\end{array}$ \\
\hline N. Obs. & 86 & 86 & 86 & 86 & 77 & 77 & 77 & 77 \\
\hline Model & linear & linear & linear & linear & linear & linear & linear & linear \\
\hline Interaction & YES & YES & YES & YES & YES & YES & YES & YES \\
\hline Controls & YES & YES & YES & YES & YES & YES & YES & YES \\
\hline Trim & $5 \%$ & $5 \%$ & $5 \%$ & $5 \%$ & $5 \%$ & $5 \%$ & $5 \%$ & $5 \%$ \\
\hline St. Errors & Cluster & Cluster & Cluster & Cluster & Cluster & Cluster & Cluster & Cluster \\
\hline
\end{tabular}

Standard errors are clustered at the national levels. ${ }^{*} p<0.1 ; * * p<0.05 ;{ }^{* * *} p<0.01$. Average individual sentiment towards the EU ranges between $O$ (anti-EU) and 10 (pro-EU). The share of anti-EU political preferences is the share of individuals in the regions who prefer a party with a negative stance towards the EU (score lower or equal to 3, on a 0-10 scale, source: CHES). The group of exposed individuals comprises low-skill workers with a number of years of schooling below the median value. Outcome variables are 2012-2014 averages.

Ex-ante, it is not obvious whether or not we should expect heterogeneous effects across the social groups. For instance, on the one hand more educated individuals might be more aware of European policies, including the regional transfers. On the other hand, low skill individuals might benefit proportionally more in terms of job creation from the infrastructural investments financed by Cohesion Policy. Exposure to globalization is likely to be a relevant source of heterogeneity. We might expect, for instance, that the segments of the population more exposed to globalization backlashes might be so estranged that Cohesion Policy transfers might just not be enough to change their perception toward the EU. We exploit the descriptive analysis we developed in Section 3.2 to investigate this hypothesis. We build a definition of individuals exposed to globalization and more prone to anti-establishment rhetoric. We identify two clusters of individuals 
that descriptive results suggest as being at polar opposites in their exposure to globalisation/technological change: the "not-exposed" and the "exposed". ${ }^{37}$

Table 7 shows that EU funding positively and significantly affect the EU perception both for the "not-exposed" and the "exposed" group. The effect is similar in magnitude for individuals whose characteristics make them more or less exposed to the negative impact of globalization. From a policy perspective, it seems particularly relevant that even the "exposed" individuals, which are those that most likely express Eurosceptic positions (see section 3.2), are significantly influenced by the transfers.

Finally, we try to give a flavour of what mechanism could be at play regarding the citizens' perception of economic integration, of which the EU can be considered a key component. We believe there are plausible mechanisms through which funds can impact EU sentiment and political preferences; on the one hand, we can hypothesize that EU funding schemes can actually make individuals perceive the benefits of economic integration and change their inherent beliefs about "globalization". On the other hand, we can think that funds will not change individuals' beliefs but might make them less likely to blame the EU, in a "don't bite the hand that feeds you" sense.

As discussed above, individuals with a more negative attitude toward the EU generally share many characteristics with those which profess anti-immigration and anti-trade sentiments, probably due to an underlying anti-globalization attitude. We exploit this common ground to provide an additional layer of robustness to our results by showing that the funds causal effect is very specific to anti-EU attitudes, reducing the concern that some unobservable factor might be driving the results. Table 8 shows indeed that at the threshold, attitudes toward migration and in their political preferences regarding trade and migration are basically unaffected by Cohesion Policy funds. These results are particularly striking considering, for instance, the large overlapping that exists between political platforms that sustain anti-EU and anti-trade positions (see Figure 3 in section 3). These results suggest that the mechanism at play is one in which funds do not affect fundamental beliefs of citizens about economic integration, but rather reduce the propensity to find in the EU a scape-goat for the economic downturn itself, or for the lack of protection from its effects.

\footnotetext{
37 The clustering is performed according to education level and occupational skill. Each group represents around $10 \%$ of the entire population. The "exposed" group comprises low-skill workers with a number of years of schooling below the median value . The "nonexposed" group is made of managers and professionals with a number of years of schooling above the median value.
} 
Table 8

RDD results: effect of EU funding on other dimensions of international integration

\begin{tabular}{|c|c|c|c|c|c|c|}
\hline Treatment Var & \multicolumn{3}{|c|}{ EU funds (1000 euro) } & \multicolumn{3}{|c|}{ Convergence Objective status } \\
\hline \multirow[t]{4}{*}{ Outcome Var } & $\begin{array}{c}\text { Pro- } \\
\text { immigration } \\
\text { sentiment }\end{array}$ & $\begin{array}{c}\text { Share of anti- } \\
\text { immigration } \\
\text { votes }\end{array}$ & $\begin{array}{l}\text { Share of anti- } \\
\text { trade } \\
\text { preferences }\end{array}$ & $\begin{array}{c}\text { Pro- } \\
\text { immigration } \\
\text { sentiment }\end{array}$ & $\begin{array}{c}\text { Share of anti- } \\
\text { immigration } \\
\text { votes }\end{array}$ & $\begin{array}{c}\text { Share of anti- } \\
\text { trade } \\
\text { preferences }\end{array}$ \\
\hline & (1) & (2) & (3) & (4) & (5) & (6) \\
\hline & 0.014 & 0.000 & -0.112 & 0.013 & -0.025 & -0.142 \\
\hline & $(0.27)$ & $(0.061)$ & $(0.082)$ & $(0.313)$ & $(0.094)$ & $(0.101)$ \\
\hline N. Obs. & 95 & 95 & 95 & 83 & 83 & 83 \\
\hline Model & linear & linear & linear & linear & linear & linear \\
\hline Interaction & YES & YES & YES & YES & YES & YES \\
\hline Controls & YES & YES & YES & YES & YES & YES \\
\hline Trim & $5 \%$ & $5 \%$ & $5 \%$ & $5 \%$ & $5 \%$ & $5 \%$ \\
\hline St. Errors & Cluster & Cluster & Cluster & Cluster & Cluster & Cluster \\
\hline
\end{tabular}

Standard errors are clustered at the national levels. ${ }^{*} p<0.1 ;{ }^{* *} p<0.05 ;{ }^{* * *} p<0.01$. Average pro-immigration individual sentiment ranges from 0 to 10. The share of anti-immigration and anti-trade political preferences is the share of individuals in the regions who prefer a party with a negative stance towards migration and international trade (score lower or equal to 3, on a 0-10 scale, source: CHES and Votewatch Europe). Outcome variables are 2012-2014 averages.

\subsection{Robustness}

Our results pass a set of common falsification checks typical of the RDD setup. As already shown, results are not sensitive to alternative specifications, some of which include controls aiming at balancing any potential residual difference at the baseline between treated and control regions, making our RDD assumptions more likely to hold. We dig further into this issue by considering RDD specifications with a quadratic polynomial in the running variable: estimates reported in Table A2 and A3 of the Appendix show consistent and stable patterns in terms of magnitude, sign and significance. ${ }^{38}$

Furthermore, as we show in Table A4 and A5 in the Appendix, our results are generally unaffected by changes in the cut-off level used to exclude data points in the tails of the forcing variable distribution. In addition to the $5 \%$ trimming used in baseline specifications, we also consider full sample estimates as well as other trimming levels $(10 \%, 15 \%)$. Further restrictions of our estimation bandwidth would come at a cost in terms of observations loss which is too large compared to our sample size. As previously discussed, we do not have reasons to believe regions managed to self-select to the left of the cut-off threshold; as already mentioned, the per-capita measure of income used by the European Commission is lagged and is based on a three-year average. Moreover, from a theoretical perspective, since the allocation rule is based on a relative cut-off, rigging the system would require a level of coordination that is simply not sustainable in equilibrium.

\footnotetext{
${ }^{38}$ In the only case in which the estimates lose significance, it is easy to see how this is likely to be due to the attempt to estimate a model which is too complex for the limited sample size of the setting.
} 
Figure 11

Placebo Estimates on 2000-2014 per-capita EU Regional Policy payments

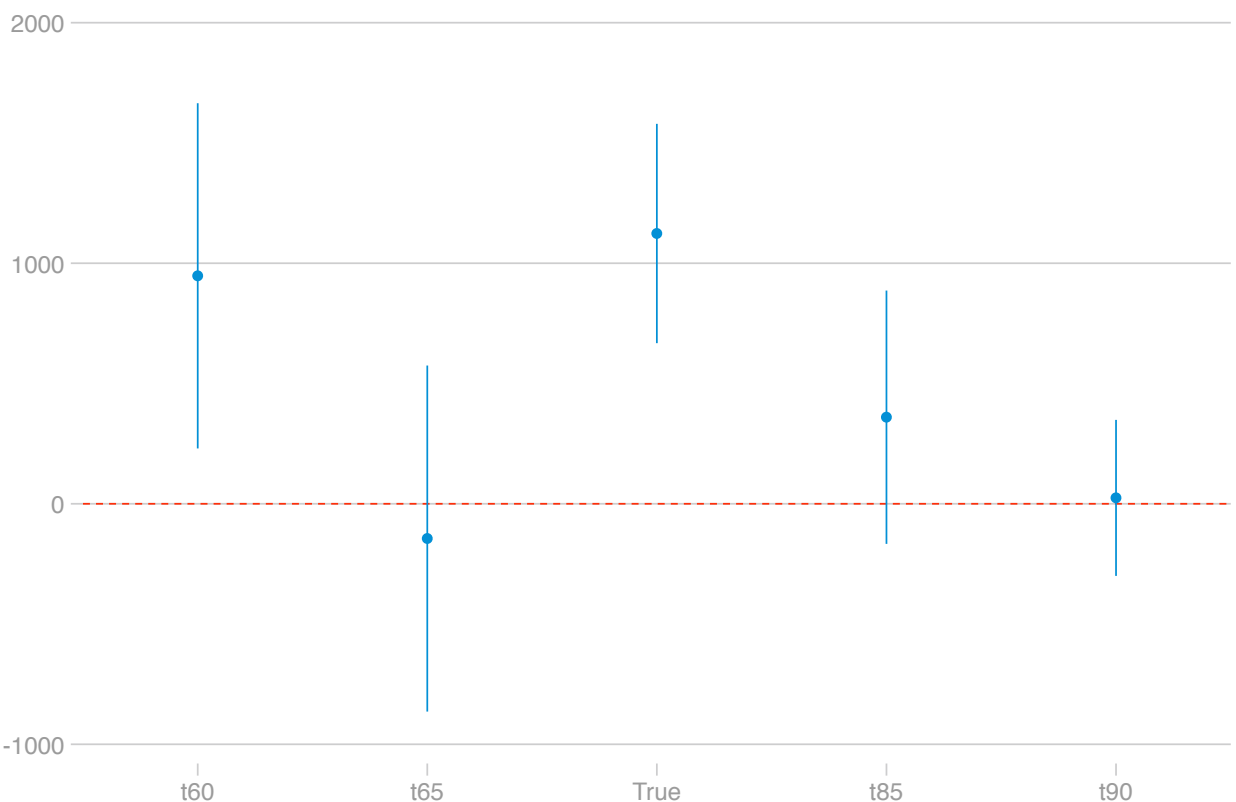

Note: Confidence intervals at the $95 \%$ significance level.

Figure 12

Placebo Estimates on pro-EU Sentiment

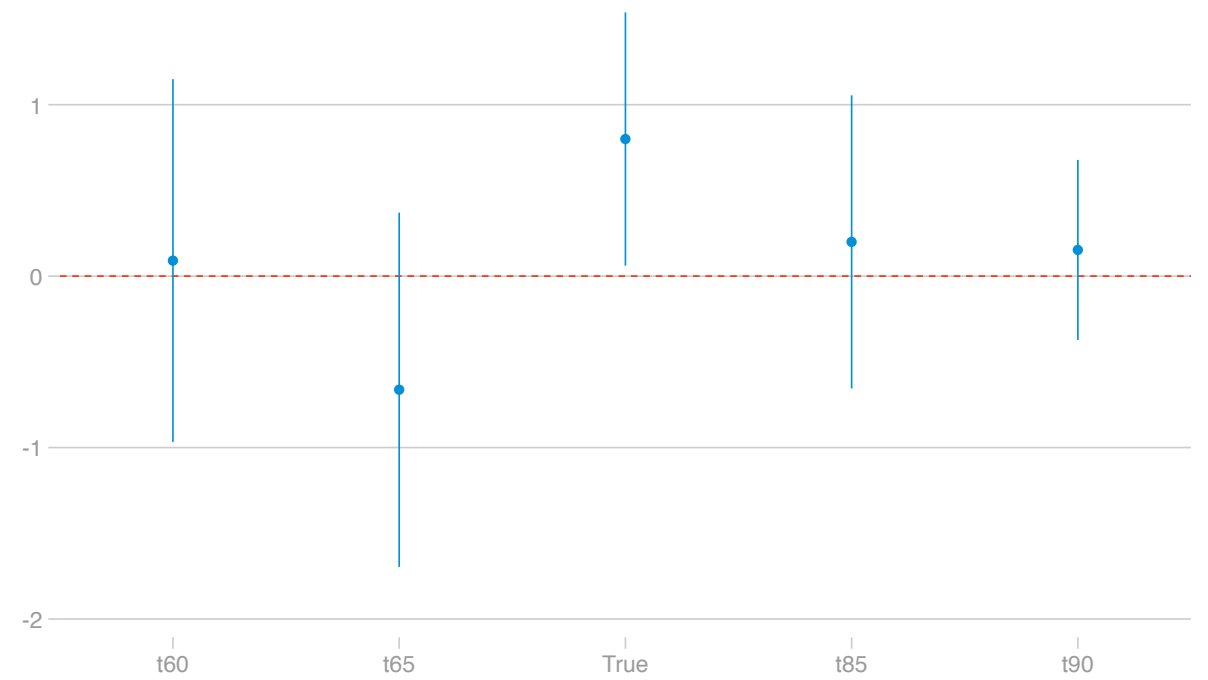

Note: Confidence intervals at the $95 \%$ significance level. Average individual sentiment towards the EU ranges between 0 (anti-EU) and 10 (pro-EU). 


\section{Placebo Estimates on anti-EU Political Preference (Share of Respondents)}

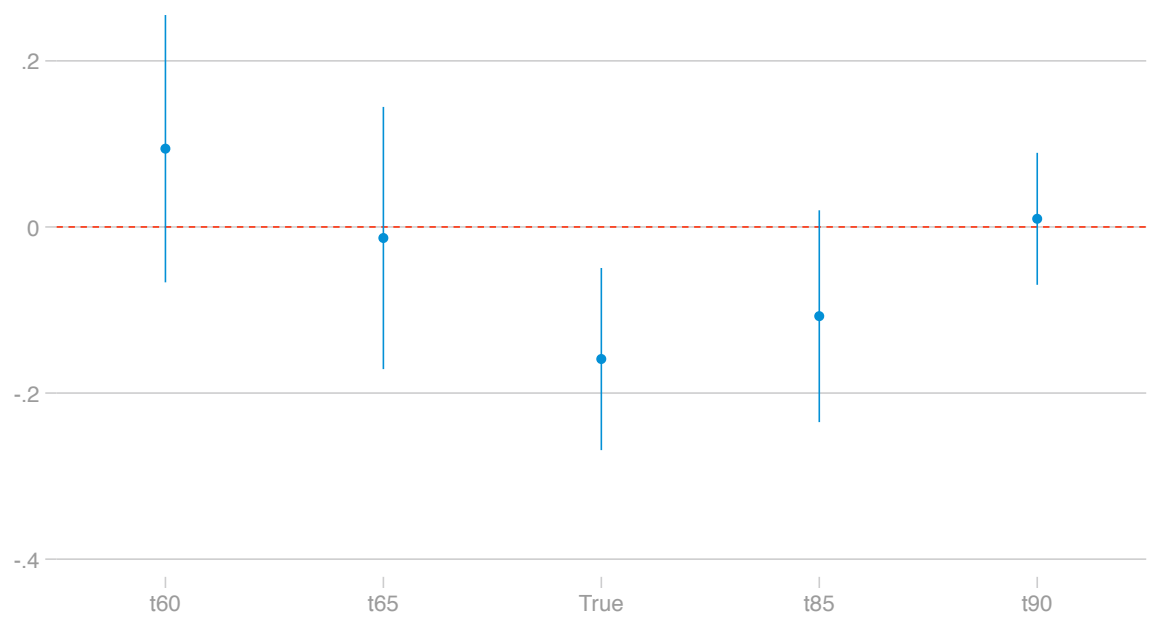

Note: Confidence intervals at the $95 \%$ significance level. The share of anti-EU political preferences is the share of individuals in the regions who prefer a party with a negative stance towards the EU (score lower or equal to 3, on a 0 -10 scale, source: $C H E S$ ).

Due to lack of data, as the ESS surveys start only in 2004, we do not have baseline values for our variable of interests (i.e. pro-EU attitude and political preference). This prevents us to exploit a proper Diff-in-Diff-RDD strategy. However, we can further validate the hypothesis that the estimated effects are indeed induced by the EU funding, and not by some pre-determined characteristics, by looking at the change in the outcomes between the first and last observation point available (2004 vs 2014). These variations are very likely to underestimate the overall impact of the programs, as some of the effects of the transfers might have been already reaped in the first five years of the treatment (from 2000 to 2004). Estimates presented in Table A6 confirm that Cohesion Policy reduce the share of individuals with particularly negative attitudes toward the EU in a statistically significant way. Strikingly, according to our baseline specification, the effect for the decade considered (2004-2014) turns out to be about $2 / 3$ of the reduction estimated for the overall 15-years' program. The effect on political preferences is also consistent. We also perform a set of falsification tests on our results. First, we check that the most substantial discontinuity in funding occurs at the $75 \%$-cut-off. Indeed, as showed in Figure 11, this seems to be the case. ${ }^{39}$ Notably, no significant discontinuity emerges at the 90\%-cut-off, that is the eligibility threshold

\footnotetext{
${ }^{39}$ Although some discontinuity emerges also at the $60 \%$ threshold, this estimate has limited reliability as only 5 regions have a GDP pc below $60 \%$ of the EU average; in any case, this potential discontinuity does not affect our baseline estimates since we exclude observations in the tails.
} 
that discriminates between the European Territorial Cooperation Objective and the Regional Competitiveness and Employment Objective. Hence, we are utterly reassured that the first-stage relationship is strong and specific to the $75 \%$-rule.

Finally, we check if jumps in the outcome variables occur only at the true treatment cut-off or also at other placebo thresholds. We plot the estimated treatment effect on two main outcomes, namely EU sentiment and anti-EU political preferences, for a set of fictitious thresholds plus the $75 \%$-one. If the $75 \%$-threshold is the true discontinuity point, then we expect its coefficient to be the maximum in the (pro)-EU sentiment graph and minimum in the anti-EU political preferences, and the only one statistically different from zero. Results of the placebo exercised are summarized in Fig. 12 and Fig. 13. Regarding pro-EU sentiment, Fig. 11 shows us that that there are no large and significant jumps at the placebo thresholds. As far as political preferences are concerned, the only significant effect is observed at the $75 \%$ cutoff for the share of individuals supporting Eurosceptic parties. In sum, we are convinced that the relationship between the forcing variable and our outcome variables of interest are not fundamentally discontinuous and that the only relevant discontinuity is generated by the Convergence Objective allocation rule.

\section{Conclusions}

In this paper we investigate whether EU transfers can buy public support for European integration, both in terms of sentiment and political preferences. To the best of our knowledge, our analysis is the first attempt to address this question by identifying a causal relationship. We focus on EU regional Cohesion Policy, within which the Convergence Objective program offers a quasiexperimental framework that allows us to single out these effects by means of an RDD approach.

We find that the EU Cohesion funds positively influence public support for European integration. It is also reflected in political preferences: our results suggest that parties with pro-EU stance benefit from the EU regional transfers scheme; the average effect is partly driven by farright nationalistic platforms which tend to be relatively less popular in Convergence Objective regions. Most notably, the Convergence Objective status does not have any sizeable effect on other attitudes that share a common ground with the Euroscepticism (i.e. anti-trade and antiimmigration), a result that strengthen our confidence in the specificity of the relation singled out by the identification strategy.

A noteworthy result is that EU transfers are appreciated by all social groups, including those highly exposed to the negative effects of globalization and technological change. This emerges despite the fact that Eurosceptic positions are more popular among these individuals both in advanced and less developed areas. This evidence supports the following policy indication: measures aiming to tackle the social discontent and the aversion toward the EU should go beyond 
the traditional "location-based" EU redistribution approach, that so far have benefitted mostly peripheral areas; more space should be given to broad-based and clearly recognizable redistributive measures, that would target disadvantaged individuals irrespectively of their region of residence. This seems suited to improve public support for European integration also in regions that are net financial contributors to the EU budget, not only in net recipient ones, an aspect that has to be also considered when evaluating the overall repercussions of redistributive policies. Measures like the European Social Fund and the European Globalization Adjustment Fund probably go in this direction, but they seem still too limited in size to make a difference.

Compared to previous evaluations, our work represents an advancement along two main dimensions: on one hand, we are the first to address the question of whether EU funds can buy EU love through a rigorous identification strategy, despite the setting's idiosyncratic limitations. On the other hand, we tackle the issue from a broad European-level perspective (i.e. not focusing on a single country or on a specific electoral outcome).

Our study focuses on the Convergence Objective funds, which are particularly relevant for their size and persistence over time. It is hard to say whether other types of EU transfers are similarly appreciated by the public opinion. At the same time, the program under study provides transfers only indirectly to the citizens; hence, it is plausible that our estimates represent a lower bound for the effect of other, more salient, types of transfers.

Notably, our analysis does not imply that the Convergence Objective program, and more generally the EU Regional Policy, are the most appropriate and effective measures to pursue the economic purposes of supporting growth and employment in disadvantaged regions. Indeed, our results on EU sentiment and voting preferences can coexist with a scenario in which transfers are economically inefficient and related to rent-seeking behaviour (Accetturo et al. 2014).

In sum, our work speaks to the ongoing debate on the future of the EU integration process, which crucially depends on citizens' support. Concerning the political implications of EU redistributive policies, our results challenge the idea that EU transfers do not play any role in shaping public attitudes toward Europe, a view that has gained in popularity after the Brexit referendum. In addition, our results, drawn from the European context, contribute to the more general discussion on the support-buying effect of public transfers from different government levels (e.g. supra-national, national, and regional). We show that even indirect transfers are an effective way to induce a more positive attitude towards the institutions responsible for the financing, an aspect that should not be disregarded in the context of policy evaluations. 


\section{Appendix}

\section{Figures:}

Figure A1

Convergence Objective regions, by programming period.

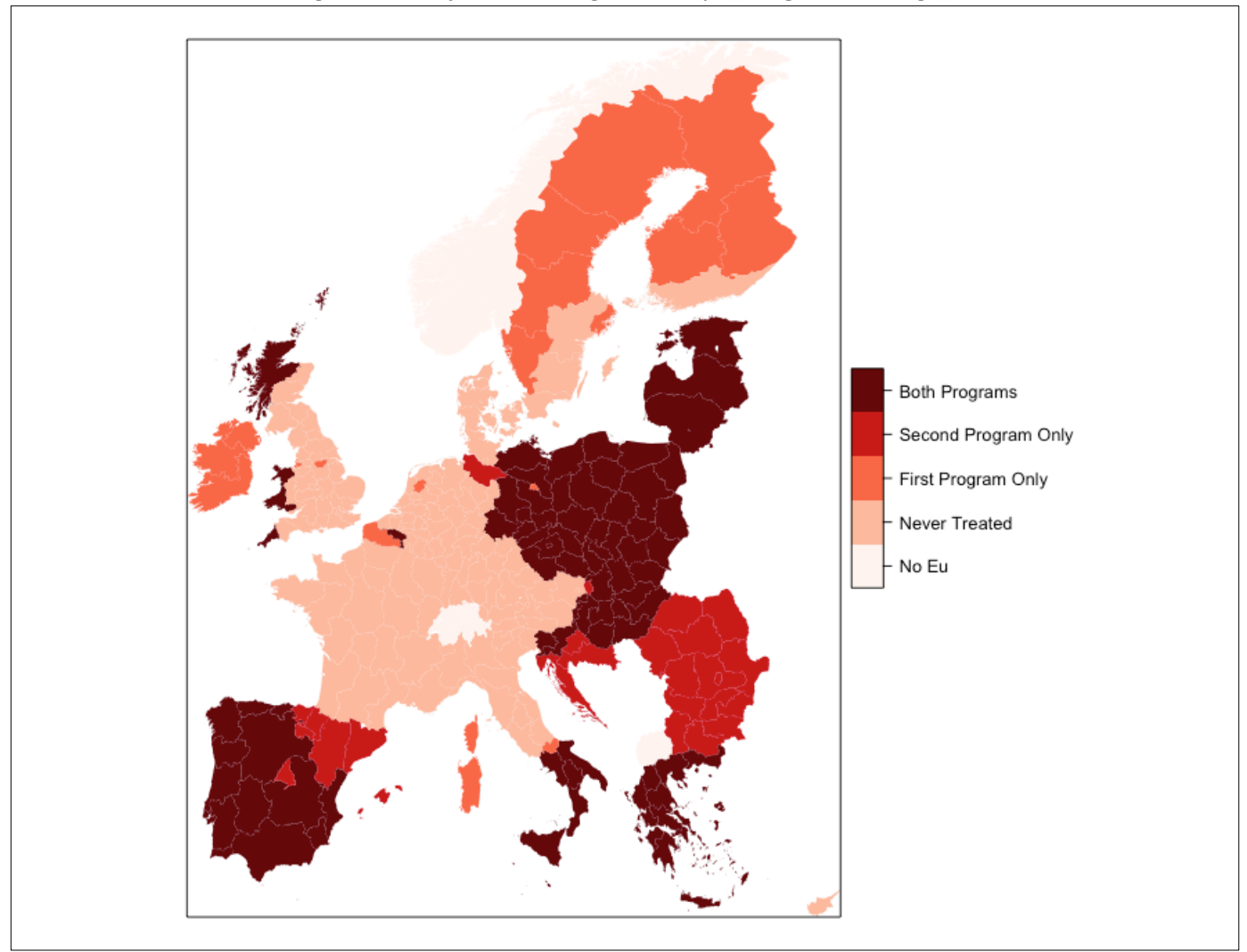

Source: European Commission

Figure A2

Convergence Objective status and First program eligibility rule, 2000-2014
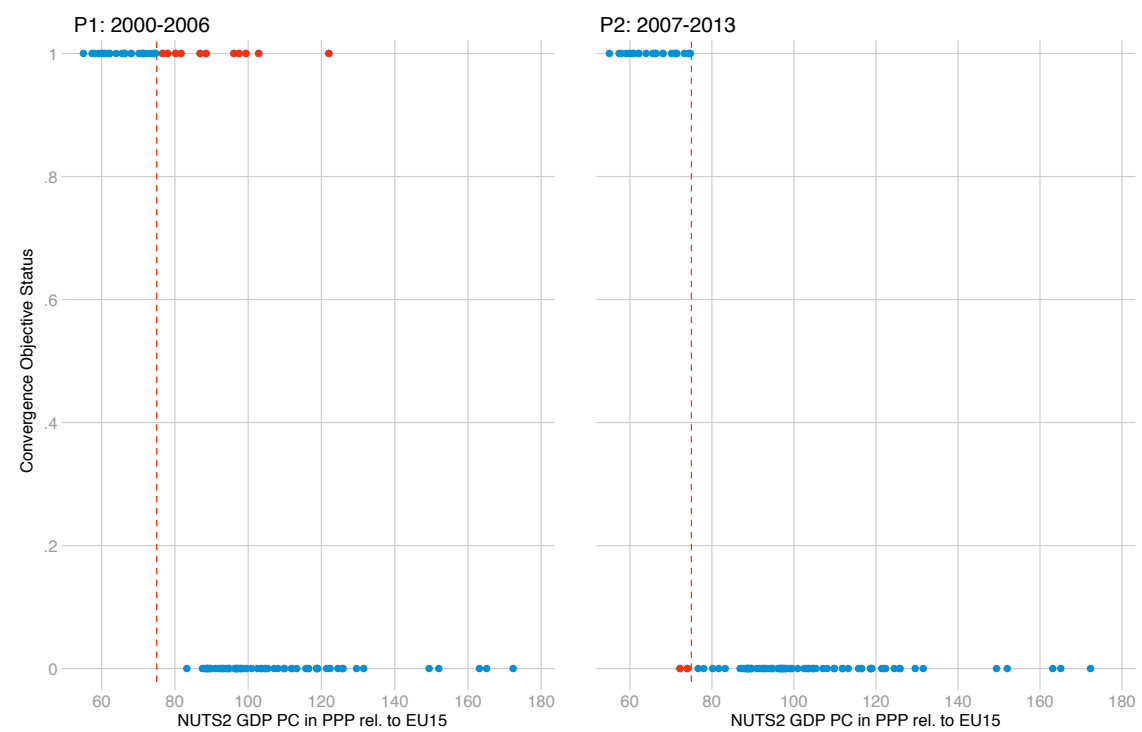
Cumulated funds from EU regional policies, per capita, 2000-2014

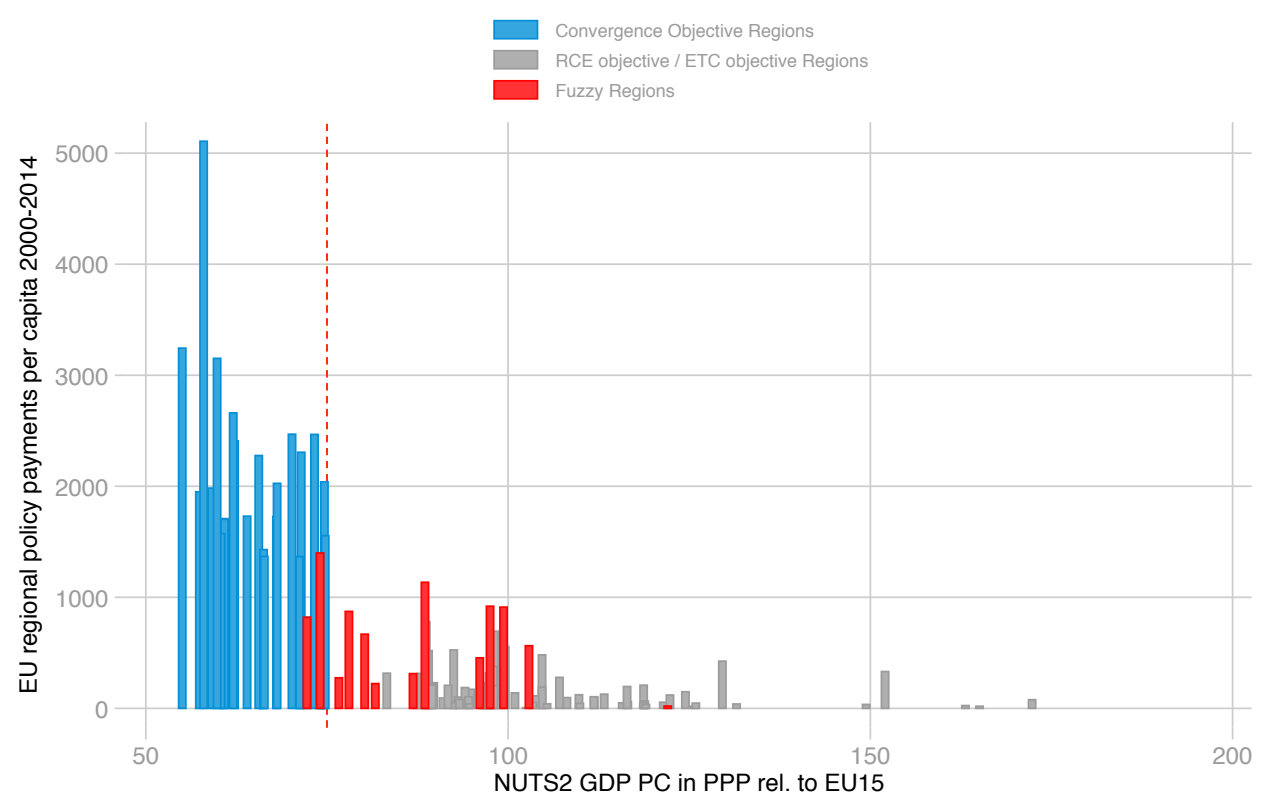

Note: $X$-axis values are the official indexing computed by the European Commission in 1999.

Figure A4

Cumulated funds from EU regional policies, \% GDP, 2000-2014

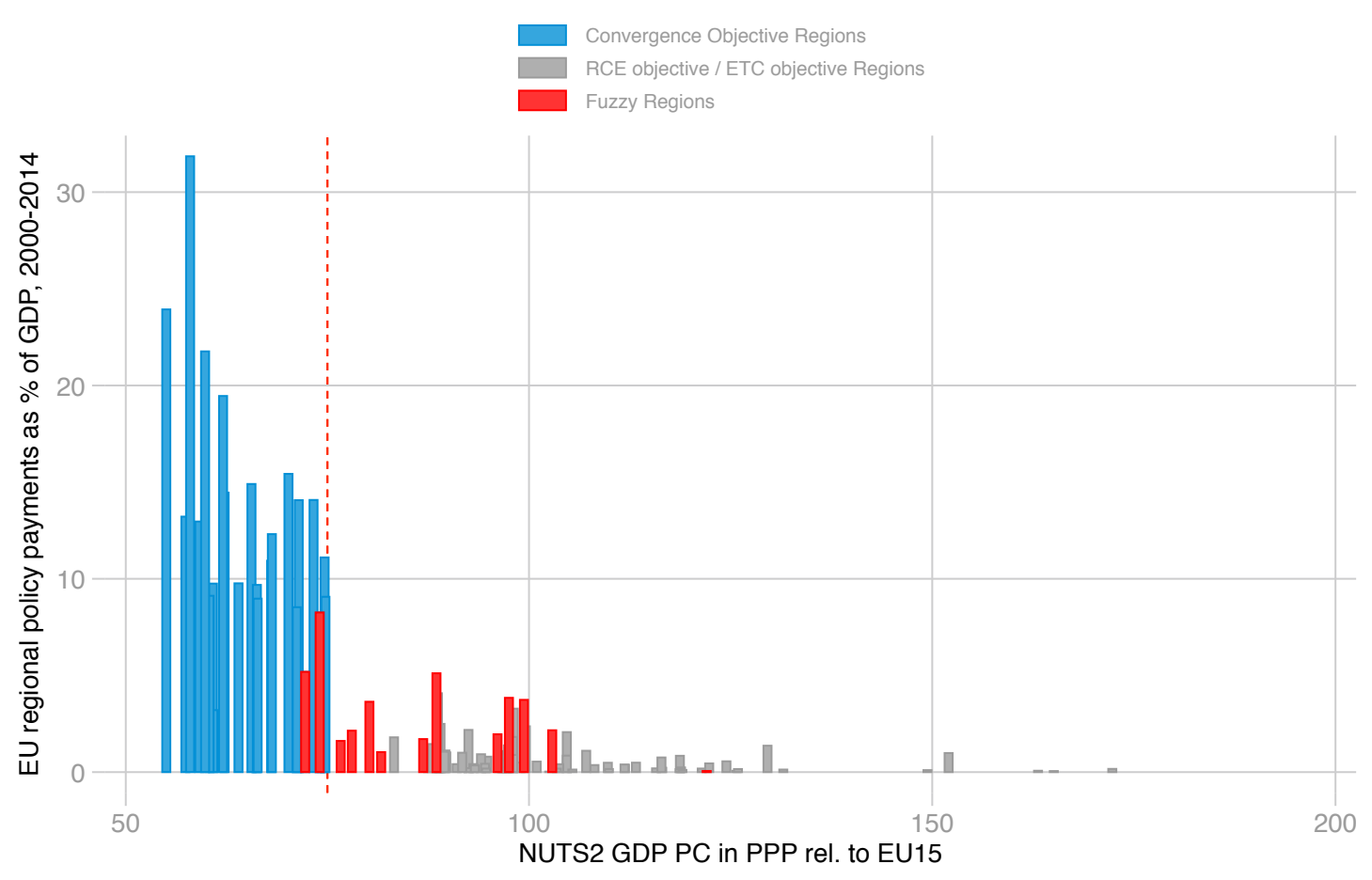

Note: $X$-axis values are the official indexing computed by the European Commission in 1999. 
Tables:

Table A1

Determinants of EU sentiment and anti-EU political preferences

(pooled data 2012-2014)

\begin{tabular}{|c|c|c|c|c|c|c|c|c|}
\hline \multirow[b]{3}{*}{ Left } & \multicolumn{4}{|c|}{ EU sentiment } & \multicolumn{4}{|c|}{ Share of anti-EU political preferences } \\
\hline & \multicolumn{2}{|c|}{ (1) } & \multicolumn{2}{|c|}{$(2)$} & \multicolumn{2}{|c|}{ (3) } & \multicolumn{2}{|c|}{$(4)$} \\
\hline & $0.398 * * *$ & (0.059) & $0.417^{* * *}$ & $(0.061)$ & -0.013 & $(0.016)$ & -0.015 & $(0.016)$ \\
\hline Tot time TV & $-0.114 * * *$ & $(0.016)$ & $-0.102 * * *$ & $(0.017)$ & $0.008 * *$ & $(0.003)$ & $0.007 * *$ & $(0.003)$ \\
\hline Time TV news & $0.138 * * *$ & $(0.022)$ & $0.102 * * *$ & $(0.02)$ & 0.001 & $(0.004)$ & 0.004 & $(0.004)$ \\
\hline Years of education & $0.048 * * *$ & $(0.007)$ & $0.044 * * *$ & $(0.007)$ & $-0.005 * * *$ & $(0.001)$ & $-0.004 * * *$ & $(0.001)$ \\
\hline Age & $-0.124 *$ & $(0.07)$ & -0.081 & $(0.066)$ & -0.001 & $(0.015)$ & -0.006 & $(0.015)$ \\
\hline Unemployed & $0.222 * * *$ & $(0.064)$ & $0.250 * * *$ & $(0.066)$ & -0.009 & $(0.017)$ & -0.014 & $(0.016)$ \\
\hline Personal Income & $0.323 * * *$ & $(0.041)$ & $0.218 * * *$ & $(0.037)$ & $-0.016 * * *$ & (0.006) & -0.007 & $(0.005)$ \\
\hline Low skill manuf. & $-0.165 *$ & $(0.087)$ & $-0.133 *$ & $(0.079)$ & $0.021 *$ & $(0.012)$ & 0.019 & $(0.012)$ \\
\hline Medium skill manuf. & 0.01 & $(0.063)$ & -0.002 & $(0.06)$ & 0.004 & (0.009) & 0.009 & $(0.01)$ \\
\hline High skill & $0.19 * * *$ & $(0.068)$ & $0.146 * *$ & $(0.066)$ & $-0.041 * * *$ & $(0.012)$ & $-0.035 * * *$ & $(0.011)$ \\
\hline Trust in politicians & & & $0.239 * * *$ & $(0.019)$ & & & $-0.021 * * *$ & $(0.003)$ \\
\hline Funded regions & 0.288 & $(0.204)$ & $0.492 *$ & $(0.268)$ & $-0.145 * * *$ & $(0.017)$ & $-0.152 * * *$ & $(0.019)$ \\
\hline Observations & 3067 & & 305 & & 16593 & & 165 & \\
\hline Year fixed effects & Y & & Y & & Y & & Y & \\
\hline Regional macroeconomic-controls ${ }^{1}$ & Y & & Y & & Y & & Y & \\
\hline Other individual controls ${ }^{2}$ & $Y$ & & Y & & Y & & Y & \\
\hline R-squared & 0.06 & & 0.1 & & 0.057 & & 0.0 & \\
\hline
\end{tabular}

Regional macroeconomic-controls include regional real income per capita level and a proxy for the regional economic cycle (3-year change in regional income). 2. Other controls include dummies for gender, retirement status, other occupational conditions (e.g. housework, under education, non-reported occupation). Pooled OLS in column 1 and 2. Pooled probit in column 3 and 4, average partial effects are reported. Individual sentiment towards the EU ranges between 0 (anti-EU) and 10 (pro-EU). The share of anti-EU political preferences is the share of individuals in the regions who prefer a party with a negative stance towards the EU (score lower or equal to 3, on a $0-10$ scale, source: CHES). Standard errors are clustered at the regional levels. ${ }^{*} p<0.1 ;{ }^{* *} p<0.05 ; * * * p<0.01$. Weighted regressions with sampling weights.

Table A2

RDD results: effects on EU sentiment, quadratic polynomial of the running variable

\begin{tabular}{|c|c|c|c|c|c|c|}
\hline \multirow{3}{*}{$\begin{array}{l}\text { Dep. Var } \\
\text { Treatment Var } \\
\text { Outcome Var }\end{array}$} & \multicolumn{6}{|c|}{ EU sentiment } \\
\hline & \multicolumn{3}{|c|}{ EU funds (1000 euro) } & \multicolumn{3}{|c|}{ Convergence Objective status } \\
\hline & (1) & $(2)$ & (3) & (4) & (5) & (6) \\
\hline Avg. EU sentiment & $\begin{array}{l}0.664 * * * \\
(0.213)\end{array}$ & $\begin{array}{l}0.721 * * * \\
(0.225)\end{array}$ & $\begin{array}{l}0.485 \\
(0.32)\end{array}$ & $\begin{array}{l}1.122 * * \\
(0.454)\end{array}$ & $\begin{array}{l}1.184 \text { ** } \\
(0.454)\end{array}$ & $\begin{array}{l}1.088^{* *} \\
(0.419)\end{array}$ \\
\hline Share of anti-EU & $\begin{array}{l}-0.088 * * * \\
(0.03)\end{array}$ & $\begin{array}{l}-0.097 * * * \\
(0.032)\end{array}$ & $\begin{array}{l}-0.081 * * \\
(0.04)\end{array}$ & $\begin{array}{l}-0.124 * * \\
(0.06)\end{array}$ & $\begin{array}{l}-0.142 * * \\
(0.056)\end{array}$ & $\begin{array}{l}-0.132 * * \\
(0.054)\end{array}$ \\
\hline N. Obs. & 98 & 98 & 95 & 84 & 84 & 83 \\
\hline Model & quadratic & quadratic & quadratic & quadratic & quadratic & quadratic \\
\hline Interaction & NO & YES & YES & NO & YES & YES \\
\hline Controls & NO & NO & YES & NO & NO & YES \\
\hline Trim & $5 \%$ & $5 \%$ & $5 \%$ & $5 \%$ & $5 \%$ & $5 \%$ \\
\hline St. Errors & Cluster & Cluster & Cluster & Cluster & Cluster & Cluster \\
\hline
\end{tabular}

Standard errors are clustered at the national levels. ${ }^{*} p<0.1 ;{ }^{* *} p<0.05 ; * * * p<0.01$. Average individual sentiment towards the EU ranges between 0 (anti-EU) and 10 (pro-EU). Share of anti-EU is the share of individuals in the regions with a sentiment towards the EU lower or equal to 3. Outcome variables are 2012-2014 averages. 
Table A3

RDD results: effect of public support for anti-EU parties, , quadratic polynomial of the running variable

\begin{tabular}{|c|c|c|c|c|c|c|}
\hline \multirow{3}{*}{$\begin{array}{l}\text { Dep. Var } \\
\text { Treatment Var } \\
\text { Outcome Var }\end{array}$} & \multicolumn{6}{|c|}{ anti-EU political preference } \\
\hline & \multicolumn{3}{|c|}{ EU funds (1000 euro) } & \multicolumn{3}{|c|}{ Convergence Objective status } \\
\hline & (1) & $(2)$ & (3) & (4) & (5) & $(6)$ \\
\hline $\begin{array}{l}\text { Share of anti-EU political } \\
\text { preferences }\end{array}$ & $\begin{array}{l}-0.145^{* *} \\
(0.058)\end{array}$ & $\begin{array}{l}-0.136 * * \\
(0.054)\end{array}$ & $\begin{array}{l}-0.130 * * * \\
(0.046)\end{array}$ & $\begin{array}{l}-0.167^{* * *} \\
(0.06)\end{array}$ & $\begin{array}{l}-0.207^{* *} \\
(0.082)\end{array}$ & $\begin{array}{l}-0.194^{* *} \\
(0.081)\end{array}$ \\
\hline N. Obs. & 98 & 98 & 95 & 84 & 84 & 83 \\
\hline Model & quadratic & quadratic & quadratic & quadratic & quadratic & quadratic \\
\hline Interaction & NO & YES & YES & NO & YES & YES \\
\hline Controls & NO & NO & YES & NO & NO & YES \\
\hline Trim & $5 \%$ & $5 \%$ & $5 \%$ & $5 \%$ & $5 \%$ & $5 \%$ \\
\hline St. Errors & Cluster & Cluster & Cluster & Cluster & Cluster & Cluster \\
\hline
\end{tabular}

Standard errors are clustered at the national levels. The share of anti-EU political preferences is the share of individuals in the regions who prefer a party with a negative stance towards the EU (score lower or equal to 3, on a 0-10 scale, source: $C H E S)$. Outcome variables are 2012-2014 averages.

${ }^{*} p<0.1 ; * * p<0.05 ; * * * p<0.01$.

Table A4

RDD results: effects on EU sentiment estimated with different trims of the tails

\begin{tabular}{|c|c|c|c|c|c|c|}
\hline \multirow{2}{*}{$\begin{array}{l}\text { Treatment Var } \\
\text { Outcome Var }\end{array}$} & \multicolumn{3}{|c|}{ EU funds (1000 euro) } & \multicolumn{3}{|c|}{ Convergence Objective status } \\
\hline & $(1)$ & $(2)$ & $(3)$ & $(4)$ & (5) & (6) \\
\hline \multirow[t]{2}{*}{ Avg. EU sentimer } & $0.562 * *$ & $0.597^{* * *}$ & $1.116 * * *$ & $0.692 * *$ & $0.916 * * *$ & $1.513 * * *$ \\
\hline & $(0.265)$ & $(0.206)$ & $(0.384)$ & $(0.336)$ & (0.279) & $(0.396)$ \\
\hline \multirow[t]{2}{*}{ Share of anti-EU } & $-0.072 *$ & $-0.094 * * *$ & $-0.127 * *$ & $-0.086 *$ & $-0.131 * * *$ & $-0.180 * * *$ \\
\hline & $(0.04)$ & $(0.025)$ & $(0.052)$ & (0.049) & $(0.034)$ & $(0.047)$ \\
\hline N. Obs. & 105 & 86 & 74 & 93 & 74 & 63 \\
\hline Model & linear & linear & linear & linear & linear & linear \\
\hline Interaction & YES & YES & YES & YES & YES & YES \\
\hline Controls & YES & YES & YES & YES & YES & YES \\
\hline Trim & NO & $10 \%$ & $15 \%$ & NO & $10 \%$ & $15 \%$ \\
\hline St. Errors & Cluster & Cluster & Cluster & Cluster & Cluster & Cluster \\
\hline
\end{tabular}

Standard errors are clustered at the national levels. ${ }^{*} p<0.1 ;{ }^{* *} p<0.05$; *** $p<0.01$. Average individual sentiment towards the EU ranges between 0 (anti-EU) and 10 (pro-EU). Share of anti-EU is the share of individuals in the regions with a sentiment towards the EU lower or equal to 3. Outcome variables are 2012-2014 averages. 
Table A5

RDD results: effects on anti-EU political preferences estimated with different trims of the tails

\begin{tabular}{|c|c|c|c|c|c|c|}
\hline Treatment Var & EU $f$ & Inds (1000 eu & & Converge & nce Objective & status \\
\hline Outcome Var & (1) & $(2)$ & (3) & (4) & $(5)$ & $(6)$ \\
\hline $\begin{array}{l}\text { Share of anti-EU } \\
\text { political } \\
\text { preferences }\end{array}$ & $\begin{array}{l}-0.116^{* * *} \\
(0.034)\end{array}$ & $\begin{array}{l}-0.108^{* * *} \\
(0.032)\end{array}$ & $\begin{array}{c}-0.112 * \\
(0.057)\end{array}$ & $\begin{array}{l}-0.155^{* * *} \\
(0.045)\end{array}$ & $\begin{array}{l}-0.181^{* * *} \\
(0.068)\end{array}$ & $\begin{array}{l}-0.187^{* * *} \\
(0.067)\end{array}$ \\
\hline N. Obs. & 105 & 86 & 74 & 93 & 74 & 63 \\
\hline Model & linear & linear & linear & linear & linear & linear \\
\hline Interaction & YES & YES & YES & YES & YES & YES \\
\hline Controls & YES & YES & YES & YES & YES & YES \\
\hline Trim & NO & $10 \%$ & $15 \%$ & NO & $10 \%$ & $15 \%$ \\
\hline St. Errors & Cluster & Cluster & Cluster & Cluster & Cluster & Cluster \\
\hline
\end{tabular}

Standard errors are clustered at the national levels. ${ }^{*} p<0.1 ;{ }^{* *} p<0.05 ;{ }^{* * *} p<0.01$. The share of anti-EU political preferences is the share of individuals in the regions who prefer a party with a negative stance towards the EU (score lower or equal to 3, on a 0-10 scale, source: $C H E S)$. Outcome variables are 2012-2014 averages

Table A6

RDD results: effect of EU funding on anti-EU sentiment and anti-EU political preferences between 2004 and 2014

\begin{tabular}{lccc|ccc}
\hline \multicolumn{1}{c}{ Treatment Var } & \multicolumn{3}{c}{ EU funds (1000 euro) } & \multicolumn{3}{c}{ Convergence Objective status } \\
\hline Outcome Var & $(1)$ & $(2)$ & $(3)$ & $(4)$ & $(5)$ & $(6)$ \\
\hline \hline Share of anti-EU & $-0.054^{* *}$ & $-0.054^{* *}$ & -0.018 & $-0.064^{* *}$ & $-0.074 * *$ & $-0.046^{*}$ \\
& $(0.027)$ & $(0.025)$ & $(0.019)$ & $(0.032)$ & $(0.03)$ & $(0.027)$ \\
& & & & & & \\
Share of anti-EU & -0.046 & -0.037 & $-0.050^{*}$ & -0.045 & -0.037 & -0.053 \\
political preferences & $(0.029)$ & $(0.026)$ & $(0.026)$ & $(0.037)$ & $(0.04)$ & $(0.053)$ \\
& & & & & & \\
\hline N. Obs. & 105 & 95 & 86 & 93 & 83 & 74 \\
\hline \hline Model & linear & linear & linear & linear & linear & linear \\
Interaction & YES & YES & YES & NO & YES & YES \\
Controls & YES & YES & YES & NO & YES & YES \\
Trim & NO & $5 \%$ & $10 \%$ & NO & $5 \%$ & $10 \%$ \\
St. Errors & Cluster & Cluster & Cluster & Cluster & Cluster & Cluster \\
\hline \hline
\end{tabular}

Standard errors are clustered at the national levels. ${ }^{*} p<0.1 ; * * p<0.05 ; * * * p<0.01$. Average individual sentiment towards the EU ranges between 0 (anti-EU) and 10 (pro-EU). Share of anti-EU measures the share of individuals in the regions with a sentiment towards the EU lower or equal to 3. The share of anti-EU political preferences is the share of individuals in the regions who prefer a party with a negative stance towards the EU (score lower or equal to 3, on a 0 -10 scale, source: CHES). Outcome variables are average changes between 2004-2006 and the end of the full program (2012-2014). 


\section{References}

Accetturo, A., G. de Blasio and L. Ricci, (2014), "A Tale of an Unwanted Outcome: Transfers and the Local Endowments of Trust and Cooperation", Journal of Economic Behavior and Organization, vol. 102 (2014), pp. 74-89

Algan, Y. , S. Guriev, E. Papaioannou, and E. Passari, (2017), "The European Trust Crisis and the Rise of Populism," CEPR Discussion Papers 12444, C.E.P.R. Discussion Papers.

Antràs, P., A. de Gortari, and O. Itskhoki (2017), "Globalization, Inequality and Welfare", Harvard Working Paper.

Anderson, C. J., and M. S. Reichert (1995), "Economic Benefits and Support for Membership in the E.U.: A Cross-National Analysis", Journal of Public Policy, Vol. 15, No. 3, pp. 231-249.

Arnorsson, A. and G. Zoega (2016), "On the Causes of Brexit", Working Papers in Economics and Finance, 1605, Birkbeck College.

Autor, D., D. Dorn, G. Hanson, and J. Song (2014), Trade Adjustment: Worker-Level Evidence, The Quarterly Journal of Economics 129(4): 1799-1860.

Bachtler, J., C. Mendez, and F. Wishlade (2013), "EU Cohesion Policy and European Integration: the Dynamics of EU Budget and Regional Policy Reform, Ashgate Publishing.

Balassone, F., S. Momigliano, M. Romanelli and P. Tommasino (2014), "Just round the corner? Pros, cons, and implementation issues of a fiscal union for the euro area", Questioni di Economia e Finanza (Occasional Papers), Bank of Italy, November, no. 245.

Becker, S. O., T. Fetzer, and D. Novy (2017), "Who Voted for Brexit? A Comprehensive DistrictLevel Analysis", Economic Policy 32(92), October 2017, pp. 601-650.

Becker, S.O., P.H. Egger, and M. Von Ehrlich, (2010), "Going NUTS: the effect of EU structural funds on regional performance", Journal of Public Economics, 94 (9-10), 578-590.

Becker, S.O., P.H. Egger, and M. Von Ehrlich, (2012), "Too much of a good thing? On the growth effects of the EU's regional policy," European Economic Review, Elsevier, vol. 56(4), pages 648668.

Becker, S.O., P.H. Egger, and M. Von Ehrlich, (2013), "Absorptive capacity and the growth effects of regional transfers: a regression discontinuity design with heterogeneous treatment effects", American Economic Journal: Econ. Policy 5 (4), 29-77.

Bénassy-Quéré, A., (2017), "Jobs union", in "Europe's Political Spring, Fixing the Eurozone and Beyond", (A. Bénassy-Quéré and F. Giavazzi ed.), a VoxEU.org Book, CEPR Press.

Bénassy-Quéré, A. and F. Giavazzi (2017), "Europe's Political Spring, Fixing the Eurozone and Beyond", Ch. 1, a VoxEU.org Book, CEPR Press.

Beugelsdijk, M. and S. C. W. Eijffinger (2005), "The effectiveness of structural policy in the European Union: an empirical analysis for the EU-15 in 1995-2001", Journal of Common Market Studies 43, 37-51.

Biancotti, C., A. Borin and M. Mancini (2017), Euroscepticism Another Brick in The Wall, mimeo, https://www.researchgate.net/publication/318420876_EUROSCEPTICISM_ANOTHER_BRICK_IN _THE_WALL. 
Boeri, T., and J. F. Jimeno, (2016), "Learning from the Great Divergence in unemployment in Europe during the crisis," Labour Economics, Elsevier, vol. 41(C), pages 32-46.

Boldrin, M. and F. Canova, (2001), "Europe's regions-income disparities and regional policies", Economic Policy 16, 207-253.

Börzel T. A. and T. Risse, (2018), "From the euro to the Schengen crises: European integration theories, politicization, and identity politics", Journal of European Public Policy Vol. 25, Iss. 1.

Brinegar, A. and S. Jolly (2005), "Location, Location, Location: National Contextual Factors and Public Support for European Integration", European Union Politics, 6(2): 155-80.

Cappelen, A., F. Castellacci, J. Fagerberg and B. Verspagen, Bart (2003), "The impact of EU regional support on growth and convergence in the European Union", Journal of Common Market Studies 41, 621-644.

Chen, J. (2008), "Are Poor Voters Easier to Buy Off with Money? A Natural Experiment from the 2004 Florida Hurricane Season." http://wwwpersonal.umich.edu/ jowei/fema/BuyingPoorVoters.pdf.

Chen, J. (2013), "Distributive Spending, Voter Partisanship, and Political Participation: A Theory of Voter Turnout as Retrospective Evaluation.", American Journal of Political Science, 57(1), pp. 200-217.

Colantone, I. and P. Stanig (2018), "Global Competition and Brexit", American Political Science Review, forthcoming.

Colantone, I. and P. Stanig (2018), "The Trade Origins of Economic Nationalism: Import Competition and Voting Behavior in Western Europe", American Journal of Political Science, forthcoming.

Corsetti, G., L. Feld, R. Koijen, L. Reichlin, R. Reis, H. Rey and B. Weder di Mauro, (2016), "Reinforcing the Eurozone and Protecting an Open Society", CEPR Press.

De Grawle, (2017), "Making the Eurozone sustainable", in "Europe's Political Spring, Fixing the Eurozone and Beyond", (A. Bénassy-Quéré and F. Giavazzi ed.), a VoxEU.org Book, CEPR Press.

Dall'Erba, S. and J. L. Gallo (2008), "Regional convergence and the impact of European Structural Funds over 1989-1999: A spatial econometric analysis", Papers in Regional Science 87: 219-244.

Diez Medrano, J. (2003), "Framing Europe: Attitudes to European Integration in Germany, Spain, and the United Kingdom", Princeton, NJ: Princeton University, Press.

Durante, R., P. Pinotti and A. Tesei (2015), The Political Legacy of Entertainment TV, Queen Mary School of Economics and Finance Working Paper 762.

Dustmann, C., B. Eichengreen, S. Otten, A. Sapir, G. Tabellini and G. Zoega, (2017), "Europe's Trust Deficit: Causes and Remedies", Monitoring International Integration 1, CEPR Press.

Ederveen, S., J. Gorter, R. deMooij, and R. Nahuis (2002), "Funds and Games: The Economics of European Cohesion Policy", CPB \& Koninklijke De Swart, Amsterdam.

Ederveen, S., H.L.F.de Groot and R. Nahuis (2006), "Fertile soil for structural funds? A panel data analysis of the conditional effectiveness of European Cohesion Policy", Kyklos 59, 17-42.

Eichcnberg, R. and R. Dalton (1993) "Europeans and the European Community: the dynamics of public support for European integration", International Organization, 47: 507-534. 
Enderlein H., E. Letta et al. (2016), "Repair and Prepare: Growth and the Euro after Brexit", Gütersloh, Berlin, Paris: Bertelsmann Stiftung, Jacques Delors Institut - Berlin and Jacques Delors Institute in Paris.

European Commission (2016a), "Measuring the impact of Structural and Cohesion Funds using the Regression Discontinuity Design, Final technical report" - Work package 14c of the Ex Post Evaluation of the ERDF and CF 2007-2013.

European Commission (2016b), "Measuring the impact of Structural and Cohesion Funds using regression discontinuity design in EU27 in the period 1994-2011", Work package 14C Ex post evaluation of Cohesion Policy programmes 2007-2013, focusing on ERDF and the Cohesion Fund.

European Commission (2017), "Reflection paper on the deepening of the Economic and Monetary Union”, COM 2017(291), 31.5.2017, https://ec.europa.eu/commission/sites/betapolitical/files/reflection-paper-emu_en.pdf .

European Council (2017), "Declaration of the leaders of 27 member states and of the European Council, the European Parliament and the European Commission", http://www.consilium.europa.eu/en/press/press-releases/2017/03/25/rome-declaration/ .

Feenstra, R. C., and G. H. Hanson (1999), The Impact Of Outsourcing And High-Technology Capital On Wages: Estimates For The United States, 1979-1990, The Quarterly Journal of Economics 114(3): 907-940.

Fischer, S., (2015), "Past, present and future challenges for the euro area, in Inflation and unemployment in Europe", Conference proceedings 21-23 May 2015, Sintra, Portugal. http://www.ecb.europa.eu/pub/pdf/other/ecbforumoncentralbanking2015en.pdf

Fidrmuc, J., M. Hulényi, and Ç. B. Tunali, (2016), “Money Can’t Buy EU Love: European Funds and the Brexit Referendum", CESIFO Working Paper N. 6107.

Foster C. and J. Frieden (2017), "Crisis of trust: Socio-economic determinants of Europeans' confidence in Government", European Union Politics.

Frieden, J. and S. Walter (2017), "Understanding the Political Economy of the Eurozone Crisis", Annual Review of Political Science 20: 371-90.

Frölich M. (2007), "Regression Discontinuity Design with Covariates", IZA DP No. 3024

Gabel M., (1998), "Public Support for European Integration: An Empirical Test of Five Theories", The Journal of Politics, Vol. 60, No. 2, pp. 333-354.

Gabel, M. and H. Palmer (1995), "Understanding variation in public support for European integration", European Journal of Political Research 27, 1: 3-19.

Gamble, A. (2017), "State capacity, populism and the EU budget", in "Quo Vadis? Identity, policy and the future of the European Union", (T. Beck and G. Underhill ed.), a VoxEU.org Book, CEPR Press.

Gross M. and M. Debus (2018), "Does EU regional policy increase parties' support for European integration?", West European Politics, 41:3, pp. 594-614.

Guiraudon, V. (2017), "The 2015 refugee crisis was not a turning point: explaining policy inertia in EU border control", European Political Science.

Guiso, L., H. Herrera, M. Morelli, and T. Sonno (2017), "Demand and Supply of Populism", CEPR Discussion Paper 11871. 
Guiso, L., H. Herrera, M. Morelli, M and T. Sonno (2018), "Global Crises and Populism: The Role of Eurozone Institutions", EIEF Working Papers Series 1806; forthcoming in Economic Policy.

Guiso, L., P. Sapienza, and L. Zingales, (2016), "Monnet's Error?”, Economic Policy 31(86): 247297.

Hobolt, S. B. and C. E. de Vries (2016), "Turning against the union? The impact of the crisis on the Eurosceptic vote in the 2014 European Parliament elections", Electoral Studies, 44. 504-514.

Hooghe, L. and G. Marks (2005) "Calculation, community, and cues: Public opinion on European integration", European Union Politics 6(4): 419-443.

Hobolt, S. B. and J. Tilley, (2014), Blaming Europe?: Responsibility Without Accountability in the European Union, Oxford University Press.

Horeth M. (1999) No way out for the beast? The unsolved legitimacy problem of European governance, Journal of European Public Policy, 6:2, pp. 249-268.

Hewstone, M. (1986), "Understanding Attitudes toward the European Community.", New York: Cambridge University Press.

Inglehart, R., J.R. Rabier, and K. Reif (1991), "The Evolution of Public Atti-tudes toward European Integration: 1970-86.",in "Eurobarometer: The Dynamics of European Public Opinion," (ed. K. Reif and R. Inglehart), London: Macmillan.

Jacob, R., Zhu, P., Somers, M., and Bloom, H. (2012). A Practical Guide to Regression Discontinuity. MDRC Working Paper.

Jensen, J.B., D. Quinn and S. Weymouth (2016), Winners and Losers in International Trade: The Effects on U.S. Presidential Voting, NBER Working Paper 21899.

Juncker J.C., D. Tusk, J. Dijsselbloem, M. Draghi and M. Schulz (2015), "Five presidents' report: completing Europe's Economic and Monetary Union", http://www.consilium.europa.eu/en/policies/emu-report-2015/.

Kalbhenn, A., and L. Stracca (2016), "Does fiscal austerity affect public opinion?", European Central Bank Working Paper Series No 1774.

Keohane, R. and S. Hoffmann (1990), "Conclusion: Community politics and institutional change". In W. Wallace (ed.), "The Dynamics of European Integration", London: Pinter.

Lee, D. S. and T. Lemieux, (2010), "Regression Discontinuity Designs in Economics", Journal of Economic Literature 48: 281-355.

Levitt, S. D., and J. M. Snyder, Jr. (1997), "The Impact of Federal Spending on House Election Outcomes." Journal of Political Economy, 105(1): 30-53.

Manacorda, M., E. Miguel, and A. Vigorito (2011), "Government Transfers and Political Support", American Economic Journal: Applied Economics, 3: 1-28.

Midelfart-Knarvik, K. H. and H. Overman (2002), "Delocation and European integration: is structural spending justified?", Economic Policy 17, 323-359.

Mayhew, D. , 1974, Congress: The Electoral Connection, New Haven: Yale University Press.

McGraw, K. M., 1991, "Managing Blame: An Experiment al Test of the Effects of Political Accounts," American Political Science Review, 85, pp. 1133-1157. 
McLaren, L. (2002) "Public Support for the European Union: Cost/Benefit Analysis or Perceived Cultural Threat?", Journal of Politics 64(12): 551-66.

Moravcsik A., 1994, Why the European Union Strengthens the State: Domestic Politics and International Cooperation, Center for European Studies Working Paper Series \#52

Pellegrini, G., F. Terribile, O. Tarola, T. Muccigrosso and F. Busillo, (2013), "Measuring the effects of European Regional Policy on economic growth: A regression discontinuity approach," Papers in Regional Science, Wiley Blackwell, vol. 92(1), pages 217-233, March.

Ringlerova, Z. (2015), "Weathering the Crisis: Evidence of Diffuse Support for the EU from a SixWave Dutch Panel", European Union Politics, 16:4.

Rohrschneider, R. (2002), "The Democracy Deficit and Mass Support for an EU-wide Government", American Journal of Political Science, 46: 463-75.

Sala-i-Martin, X., (1996), "Regional cohesion: evidence and theories of regional growth and convergence", European Economic Review, 1325-1352.

Schuman Report on Europe (2013), "State of the Union 2013", https://www.robertschuman.eu/en/bookshop/0200-schuman-report-on-europe-state-of-the-union-2013 .

van Erkel, P. F.A., and T. W.G. Van Der Meer (2016), "Macroeconomic Performance, Political Trust and the Great Recession: A Multilevel Analysis of the Effects of within-Country Fluctuations in Macroeconomic Performance on Political Trust in 15 EU Countries, 1999-2011", European Journal of Political Research, 55:1, 177-197. 